English Language and Linguistics, 25.4: 767-797. (C) The Author(s), 2020. Published by Cambridge University Press. This is an Open Access article, distributed under the terms of the Creative Commons Attribution licence (http://creativecommons.org/licenses/by/4.0/), which permits unrestricted re-use, distribution, and reproduction in any medium, provided the original work is properly cited.

doi: $10.1017 / \mathrm{S} 1360674320000325$

\title{
FOOT-fronting and FOOT-STRUT splitting: vowel variation in the East Midlands ${ }^{1}$
}

\author{
SANDRA JANSEN \\ Paderborn University \\ and \\ NATA LIE B RABER \\ Nottingham Trent University
}

(Received 5 December 2019; revised 21 July 2020)

\begin{abstract}
This article investigates the status of the FOOT-STRUT split in the counties of Leicestershire, Nottinghamshire and Derbyshire in the East Midlands of England. The East Midlands area is a linguistic transition zone between northern English varieties with a phoneme inventory of five short vowels, where FOOT and STRUT are represented by the same phoneme, and southern English varieties which have the FOOT-STRUT split and therefore six short vowels. However, a lack of research on the distribution of the FOOT and STRUT vowels in the East Midlands exists and to fill that gap, this article examines the possible diffusion of the split northwards as predicted by Trudgill (1986). Reading-passage data, stratified by age group, sex and location is used to provide an apparent time, multilocal view on the distribution of the two vowel categories. Surprisingly, the changes that we notice do not concern the increasing distance between FOOT and STRUT but mainly FOOTfronting in Leicestershire and Nottinghamshire and STRUT-retraction in Derbyshire which leads to an increase in overlap between FOOT and STRUT in all three counties.
\end{abstract}

Keywords: FOOT, STRUT, phonemic split, East Midlands, southern English, northern English, FOOT-fronting

\section{Introduction}

One of the main distinguishing features between contemporary northern and southern UK English varieties is the difference in the short vowel system (Trudgill 1986: 58-9; Hughes, Trudgill \& Watt 2005: 59). While northerners have the same phoneme $/ \mho /$ for the lexical sets FOOT and STRUT, southerners distinguish $/ \mho /$ and $/ \Lambda /$ for FOOT and STRUT (Wells $1982 \mathrm{~b}$ : 337), i.e. for northerners the words putt and put are homophones while southerners pronounce these words differently.

\footnotetext{
${ }^{1}$ We would like to thank the editors of $E L L$ and two anonymous reviewers for their comments, which greatly improved the article. We would also like to thank Nicholas Flynn whose contribution to earlier work on the topic inspired this study, Joey Stanley for his online R tutorials and the audience of the 'Perspectives on phonemic splits in English' panel at ICLaVE 10 for their helpful remarks.
} 
Middle English showed no such distinction (Wells 1982a: 196) and this split is a relatively recent change which started in the seventeenth century in London in which

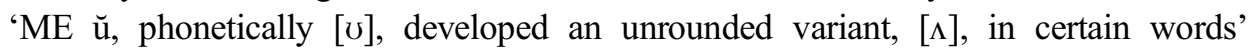
(Chambers \& Trudgill 1998: 106; Beal 2008: 131). Wells (1982a), Harris (1996) and Turton \& Baranowski (2020) provide an overview of the different stages of the FOOTSTRUT split. Beal comments that the development of the FOOT-STRUT split could be described as change from below and that the lack of the split may not have been recognised as a 'shibboleth of northern speech' until the middle of the eighteenth century (Wales 2006: 103; Beal 2012b: 8, 131).

Disagreement exists about the exact geographical distribution of the FOOT-STRUT isogloss; Wells (1982a: 197), for example, comments that the split has not taken place 'in broad accents of the north of England' and that 'we cross from the south to the linguistic north at the point where we pass the northern limits (in broad local accents) of the FOOT-STRUT Split and of BATH Broadening' (Wells 1982b: 349). Upton \& Widdowson (1996: 27) comment that it distinguishes 'Northern and North Midland speakers from those of the South and South Midlands', while Clark (2008) states that the FOOT-STRUT isogloss clearly runs to the South of the West Midlands. In all cases, this isogloss runs near to the East Midlands, making it of linguistic interest as this region is often described as a transition zone between the north and the south (Trudgill 1986; Chambers \& Trudgill 1998). Drummond (2012: 71) comments that there is variation of the STRUT vowel in the north, particularly for those higher up the social classes, where it can be found to be intermediate between the FOOT and STRUT vowel. Wells classifies 'northern' as 'midlands and northern' (Wells 1982b: 349) but also classifies the linguistic north as everything north of the Severn-Wash line (Wells 1982b: 350) and states that this line is the isogloss for the FOOT-STRUT split (Wells 1982b: 351).

The East Midlands is often underrepresented in research on linguistic variation and seems to be a linguistic no-man's land (Upton 2012: 258). Several studies and descriptions miss out the region altogether (e.g. Britain 2007; Kortmann \& Upton 2008; Ferragne \& Pellegrino 2010). Upton comments that this region 'might be thought to warrant attention in its own right rather than being thought of as a mere junction between contrasting varieties' (Upton 2012: 262). Only recently have sociolinguists started to cover this area, e.g. Flynn (2012), Braber (2014, 2015), Braber \& Flynn (2015) and Braber \& Robinson (2018). In other areas of the country, which are also part of the transition zone between the north and the south, the FOOT-STRUT split has been investigated in more detail, e.g. Chambers \& Trudgill in East Anglia (1998) and Britain in the Fens $(1991,2002)$.

In addition to the northern and southern forms, Chambers \& Trudgill (1998: 110-13; see also Trudgill 1983: 49-51; 1986: 59-62; Upton 1995, 2012) differentiate between mixed lects and fudged lects in the transition zone between the north and the south. Speakers are said to use mixed lects when their pronunciation varies between $[\mathrm{U}]$ and $[\Lambda]$ and fudged lects when they produce 'a phonetic compromise' (Hughes et al. 2005: 60) transcribed as $[\gamma]$ (Trudgill 1986; Chambers \& Trudgill 1998) or [ə] for STRUT 
(Beal 2010: 13; see also Braber \& Flynn 2015: 384). Therefore, the use of the lowered variant is not an indicator for a phonemic split between FOOT and STRUT.

Wells (1982a: 132, 196-9; 1982b: 351-3) states that the FOOT-STRUT split is generally not found in the Midlands but that some speakers may show intermediate stages where the STRUT vowel produced may be perceptually different from both $[U]$ and $[\Lambda]$ or a hypercorrect avoidance of $[v]$ in FOOT words. Docherty \& Foulkes (1999) claim that STRUT is / $\mho /$ in Derby but may be realised as [ə] in more self-conscious speech styles, particularly by women. Hughes et al. (2005: 71) describe the split only for the South Midlands, while the north-west Midlands, East Midlands and West Midlands do not have the distinction between FOOT and STRUT. The discussion of their representative Leicester speaker shows that this speaker has no distinction between put and putt, both are realised with [U] (Hughes et al. 2005: 91). They speculate that due to the influence of RP many northern English speakers have a STRUT vowel between $/ \mho /$ and $/ \Lambda /$ which is schwa like (Hughes et al. 2005: 60). Trudgill (1986: 59) claims that the six short vowel system and therefore the phonemic split between FOOT and STRUT is gradually diffusing northwards at the cost of the five short vowel system. Recent dialectological accounts such the English Dialect App data (see Leemann et al. 2018) and Mapping variation in English in the UK (MacKenzie et al. 2014) reveal that this might be the case, but the results are based on a very limited data set of lexical items and the data are skewed towards younger speakers.

Very few sociophonetic studies concerning the FOOT-STRUT split in the transition zone have been conducted so far. Based on single-speaker measurements, Ferragne \& Pellegrino (2010: 9f.) report the split for Birmingham in the West Midlands. Turton \& Baranowski (2020) conduct a variationist study in Manchester and focus on the distribution of FOOT and STRUT according to social class. They conclude that only very few people, mainly belonging to the highest social class, have the phonemic distinction between FOOT and STRUT. An initial account of FOOT-STRUT variation in the East Midlands is provided by Braber \& Flynn (2015: 384). They state that for a number of speakers variation in STRUT exists between $/ \mho /$ and $/ \Lambda /$, as the vowel produced is not $[\Lambda]$ but has a more central, schwa-like quality. They also suggest that 'this is an area that warrants further exploration to add to the small amount of existing research on FOOT/ STRUT distinction in the area in close proximity to the FOOT-STRUT isogloss' (Braber \& Flynn 2015: 386). Many of the studies seem to rely on phonetic distinction between the vowels to distinguish the status of the two phonemes, while Turton \& Baranowski (2020) argue that even speakers who show a phonetic difference between the two lexical sets due to co-articulation with adjacent segments might not have the split. Rather, they may simply show the phonetic precursor to the split, replicating the pattern that those in the south would have had before the split was innovated.

In terms of present-day perception, the lack of the split seems to be very salient to southerners but less so for northerners. Beal claims that the lack of the split is not salient to those who do not have the split, although it is frequently stigmatised by those who do have it (Beal 2012a: 70; 2012b: 7, 12-13). Wells argues that 'Many educated northerners ... would not be caught dead doing something so vulgar as to pronounce 
STRUT words with [u]' (Wells 1982b: 354) and Wales (2006: 210) comments that the northern $/ \mho /$ is likely to remain an important and salient marker in the north. The lack of the split is enregistered in certain phrases, e.g. oop north or fook (Beal 2012b: 6).

The previous discussion highlights the need for a more detailed investigation of the distribution of FOOT-STRUT in the East Midlands. In this article we therefore provide a multilocal analysis of it in order to explore the occurrence of the FOOT-STRUT split in three counties of the East Midlands: Leicestershire, Nottinghamshire and Derbyshire.

Furthermore, investigating the variation and change in the FOOT-STRUT split has theoretical implications in that the spread of the distinction between FOOT and STRUT means that speakers need to acquire a new phonemic category. Nycz (2018) discusses the acquisition of splits in the context of Canadians who moved to New York and acquired parts of the LOT/THOUGHT distinction. Mobile speakers are a good testing ground for the acquisition of splits. Nycz argues that speakers can acquire a small distinction due to gradual increase of the distinction in individual lexical items. She concludes that this situation does not result in a category-level split. Given the above description, the East Midlands is for that reason a good testing ground for the development of splits in the wild.

\section{FOOT-STRUT in the SED, MMB and BBC Voices data}

In order to provide a real-time perspective, three datasets held by the British Library are consulted here to establish the use of FОот and STRUT in the East Midlands in the first half of the twentieth century: the Survey of English Dialects (SED, Orton et al. 1962-71); the Millennium Memory Bank (MMB) and BBC Voices. For the SED the informants were mainly non-mobile older rural men who were recorded in the 1950s. The MMB data were collected during 1998 and 1999, when forty BBC local radio stations recorded personal oral histories from a broad cross-section of the population. Interviews concentrated on everyday life. The $B B C$ Voices project provided a snapshot of the language in the UK at the start of the twenty-first century. BBC Voices contains a set of group conversations about language, accent and dialect recorded in locations across the UK by BBC Local Radio in 2004 and 2005. These recordings are included in full on the British Library website, as well as metadata about the speakers, abstracts of the contents of the interviews and for some of them, linguistic descriptions of the recordings, including information about phonetic, lexical and morpho-syntactic features. These recordings were analysed auditorily by the British Library and also by the authors of this study. An overview of STRUT from the SED, MMB and BBC Voices data from the East Midlands can be found in table 1. We follow Foulkes \& Docherty (1999) in the representation of the variants by organising them in order of quantity.

In the case of FOот, there is relatively little to say as almost all speakers are using the expected $[v]$ variant with very little exception. Hence, we did not include this information in table 1 . STRUT is mainly realised as $[\mho]$ and hardly any variation exists for the speakers in Nottinghamshire and Derbyshire in all three datasets. Speakers in Leicestershire, however, show more variation. There are examples of both $[\mho]$ and $[\Lambda]$ 
Table 1. STRUT in the SED, MMB and BBC Voices East Midlands recordings

\begin{tabular}{llll}
\hline \hline & SED & MMB & BBC Voices \\
\hline Nottinghamshire & $v$ & $v$ & $v$ \\
Leicestershire & $v \sim \Lambda \sim \gamma \sim \mathrm{p}$ & $v \sim \rho$ & $v \sim \Lambda \sim \rho \sim \theta$ \\
Derbyshire & $v$ & $v$ & $v \sim \mathrm{p}$ \\
\hline \hline
\end{tabular}

as well as two occurrences of $[\gamma]$, which implies the existence of a fudged vowel, and one of [p], which appeared in the word 'mother'. It has been suggested (Jonnie Robinson, personal communication) that the second might be a relic of Middle English and can sometimes be found in the West Midlands (mom for mum, for example). This pronunciation has also been noted in Alan Sillitoe's literary works, for example bugger is spelt as bogger in Saturday Night and Sunday Morning (1958), which is set in Nottingham.

The increased variation in Leicestershire indicates that the five-vowel system seems slowly to be replacing the six-vowel system, as Trudgill (1986: 59) has predicted. At the same time, the lack of the split was a characteristic in the varieties of Nottinghamshire and Derbyshire in the three data sets stretching from the middle of the twentieth century to the first decade of the twenty-first century.

However, we do not know sociophonetic details about the status of the FOOT-STRUT split in the East Midlands in the second decade of the twenty-first century. Hence, this article addresses the following research questions:

1. What are the acoustic properties of FOOT and STRUT in the three counties? How much overlap exists between the variables?

2. What is the geographical and apparent time distribution of FOOT and STRUT in the three counties?

3. Is a diffusional pattern of the FOOT-STRUT split observable in the three counties?

\section{Methodology}

In order to address the research questions, we created a speech sample of 60 speakers, 20 speakers each from Leicestershire, Nottinghamshire and Derbyshire (see figure 1 and table 2). The sample has been stratified according to age, sex and place. Speakers in the older age category were over 55 years old, speakers in the younger age category were between 18 and 25 years old. Each speaker read a text passage (see Appendix 1) which contained 13 lexical items with STRUT vowels and 18 lexical items with FOOT vowels; the passage was then read a second time.

Recordings were conducted by the second author and students from Nottingham Trent University who were local to one of the three counties under study in this project. The people who carried out recordings were briefed thoroughly about recording conditions and placement of the recording device. The recordings were made on phones, recorded 


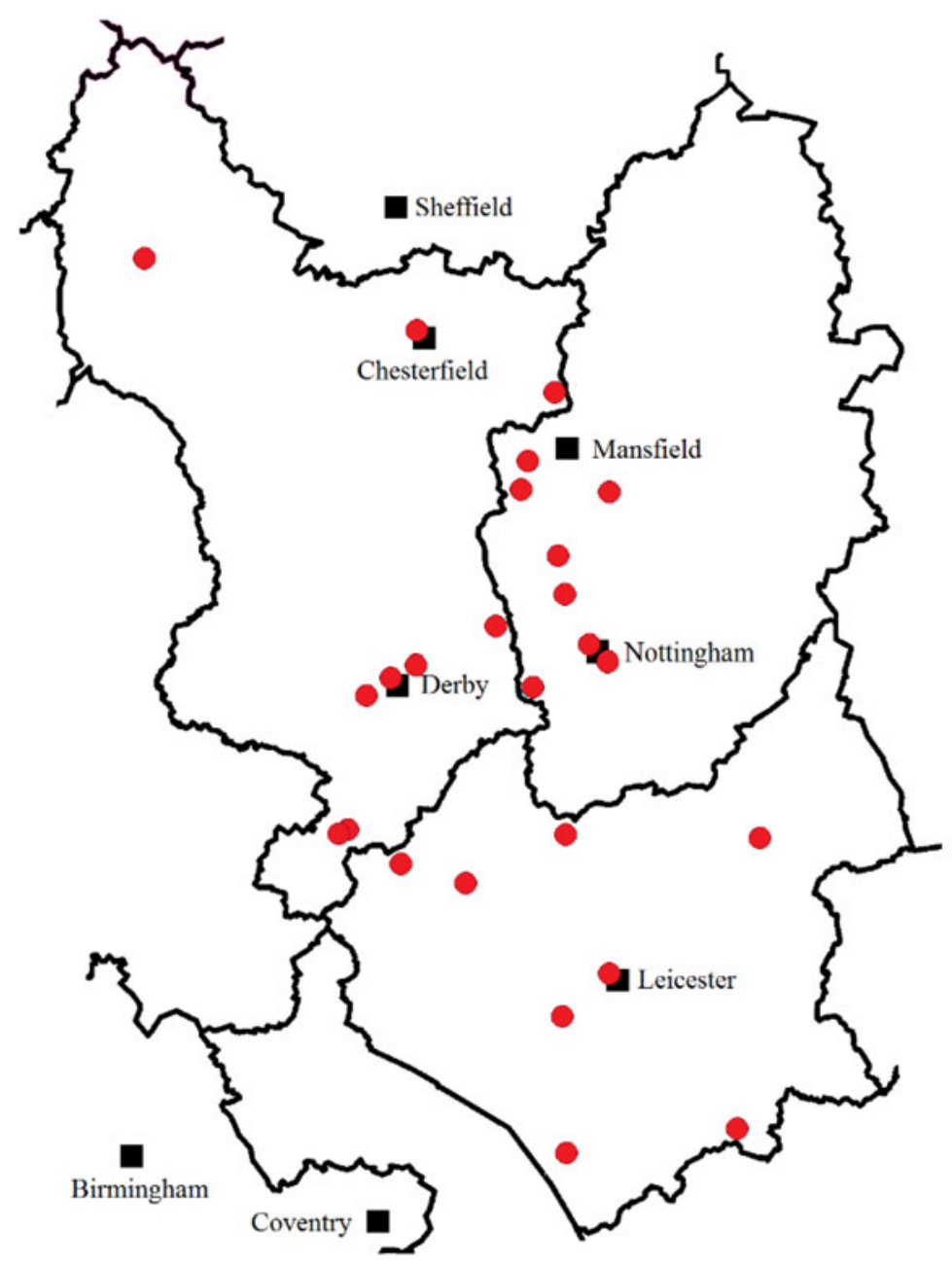

Figure 1. Map of East Midlands with speaker locations

in mp4 format, then converted to .wav with the Macbook converter. Each recording was

Table 2. Speech sample stratified by age group, sex and county

\begin{tabular}{|c|c|c|c|c|c|c|}
\hline & \multicolumn{2}{|c|}{ Leicestershire } & \multicolumn{2}{|c|}{ Nottinghamshire } & \multicolumn{2}{|c|}{ Derbyshire } \\
\hline & Young & Old & Young & Old & Young & Old \\
\hline M & 5 & 5 & 5 & 5 & 5 & 5 \\
\hline $\mathrm{F}$ & 5 & 5 & 5 & 5 & 5 & 5 \\
\hline Total & 10 & 10 & 10 & 10 & 10 & 10 \\
\hline
\end{tabular}


auditorily checked for quality by the first author. After that the recordings were transcribed in ELAN (Sloetjes and Wittenburg 2008).

The sound files were subjected to forced alignment of segments with FAVEalign (Rosenfelder et al. 2011), an automatic alignment tool adapted for sociolinguistic research. The program facilitates the automatic conversion of an orthographic transcription into phonemes by looking up words and their transcriptions in a pronunciation dictionary. Following the alignment, we used FAVEextract (Rosenfelder et al. 2011), a program which allows the automatic extraction of formant measurements for a given speaker in an aligned sound file. This was used to extract all vowel tokens of the reading passage, which had a duration of at least $50 \mathrm{~ms}$. These were measured at the midpoint and included in the analysis. Overall, 2,831 tokens were extracted, of which 1,111 belong to the STRUT set and 1,720 to the FOOT set. To compare vowel realisations between speakers, vowel measurements were normalised with FAVE's built-in transformation based on Lobanov (1971).

\section{Data analysis: overlap between FOOT and STRUT}

In order to investigate the status of FOOT and STRUT, we decided to use overlap measurements. Different methods to measure the distribution of overlap exist. Johnson (2015) discusses alternative measures such as Euclidean distance (e.g. Herold 1990; Evanini 2009; Johnson 2010) and Pillai’s trace (e.g. Hay et al. 2006; Nycz \& Hall-Lew 2014), but explains that Bhattacharyya's Affinity (Bhattacharyya 1943) is preferable to these measurements because it is less sensitive to nested, crossed, skewed or imbalanced distributions, unlike Pillai scores (Johnson 2015). Bhattacharyya's Affinity measures overlap between two cohorts in a two-dimensional space, which makes it an ideal measurement for F1/F2 vowel distributions. Recent studies by Strelluf (2016, 2018), Stanley \& Renwick (2016) and Warren (2018) use this measurement for overlap in vowel mergers.

Bhattacharyya's Affinity measures the overlap between two distributions on a scale from 0 to 1 , generating a coefficient of 0 if no overlap exists between the two distributions and a coefficient of 1 for distributions which overlap completely, which is an advantage over Pillai scores. Bhattacharyya's Affinity is included in the \{adehabitatHR\} package for R (Calenge 2006; R Core Team 2015). However, unlike Pillai's trace, Bhattacharyya's Affinity does not return a significance score.

Figure 2 shows a scatterplot of FOOT and STRUT in the three counties. At first sight, the distribution between the different counties looks very similar, with the majority of FOOT and STRUT tokens overlapping but nevertheless not a complete overlap. Table 3 provides the overall Bhattacharyya's Affinity measurement for each county. The values confirm the large but not complete overlap between FOOT and STRUT in every county. As previously mentioned, Turton \& Baranowski (2020) argue that speakers might not have the split, even though phonetic differences between the two lexical sets exist which are due to co-articulation with adjacent segments. Hence, a complete overlap with a value of 1 is not expected. On the other hand, the value can only provide 

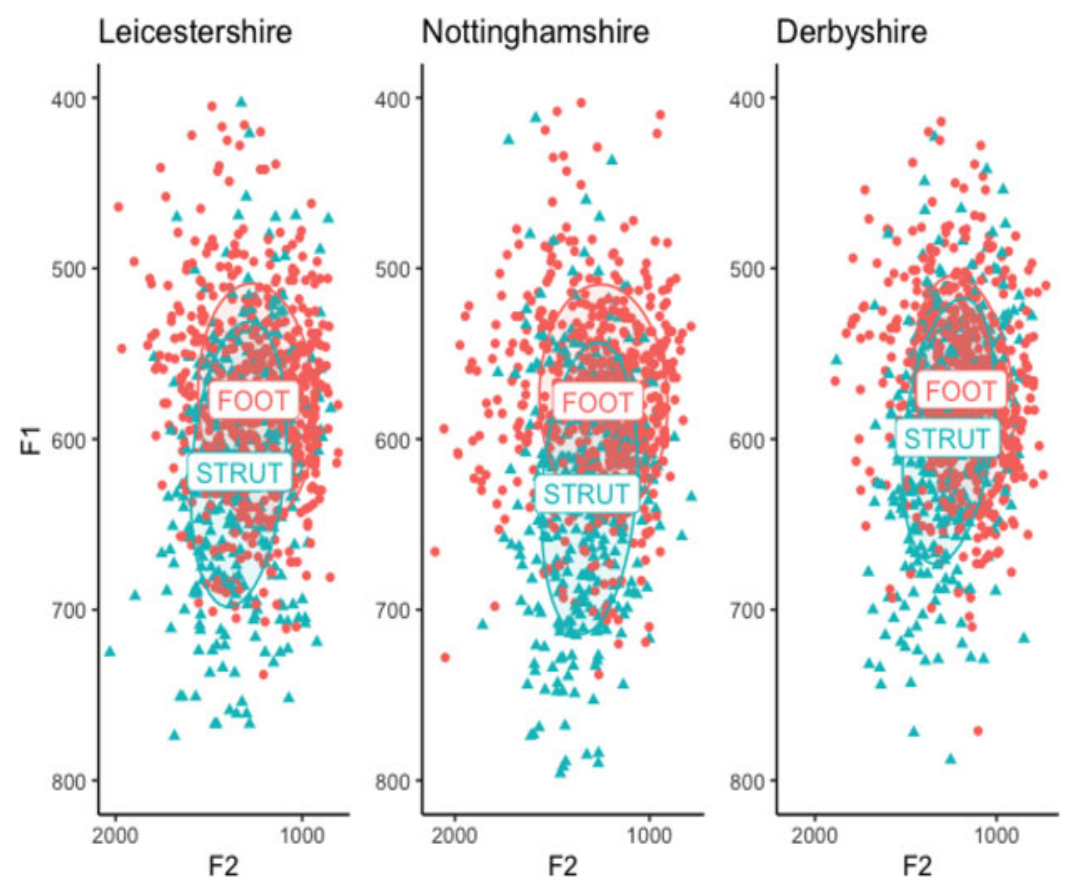

Figure 2. Overlap of FOOT and STRUT in Leicestershire, Nottinghamshire and Derbyshire

Table 3. Bhattacharyya's Affinity for the three counties

\begin{tabular}{ll}
\hline \hline Overall & .92999 \\
Derbyshire & .9444 \\
Leicestershire & .9306 \\
Nottinghamshire & .8987 \\
\hline \hline
\end{tabular}

information about the (changes in the) overlap, not whether the speakers have a phonemic split or not. However, a decrease in the overlap of FOOT and STRUT might hint at a phonemic split.

The overlap in Derbyshire is higher than for Nottinghamshire and Leicestershire, and Nottinghamshire displays a lower overlap than Leicestershire, which comes as a surprise if we assume that the increase of the split (i.e. less overlap) is a northward movement. Welch's two-sample $t$-test of Bhattacharyya's Affinity for the three counties ${ }^{2}$ returns a significant difference between Derbyshire and Nottinghamshire $[\mathrm{p}=.0363]$ but not between Derbyshire and Leicestershire [ $\mathrm{p}=.209]$ and Leicestershire and Nottinghamshire $[\mathrm{p}=.3184]$.

\footnotetext{
2 Input to the $t$-test: Bhattacharyya's Affinity measurements for individuals as presented in tables 5, 6 and 7 .
} 
Table 4. Bhattacharyya's Affinity for age groups in the different counties

\begin{tabular}{lll}
\hline \hline County & Old & Young \\
\hline Derbyshire & .9158585 & .9590346 \\
Leicestershire & .8841179 & .9497770 \\
Nottinghamshire & .8501675 & .9238492 \\
\hline \hline
\end{tabular}

What is surprising is that the overlap seems to be lower for older speakers than for younger speakers in the three counties (see table 4). This means that the overlap between FOOT and STRUT increases across apparent time. At first sight, this finding is contrary to Leemann et al.'s (2018) finding that the split is slowly expanding northwards.

Following this, the vowel distribution and overlap for each of the three counties was investigated separately. We started with the northernmost county, Derbyshire. Figure 3 presents the distribution of FOOT and STRUT in Derbyshire in scatterplots with the label representing the midpoint of both phonemes, which seem to move towards each other in apparent time, i.e. the vowel quality of both phonemes is more similar for younger speakers than for the older speaker group.

To gain a full picture in terms of individual variation, Bhattacharyya's Affinity for each speaker was calculated (see table 5), revealing that none of the speakers in the Derbyshire
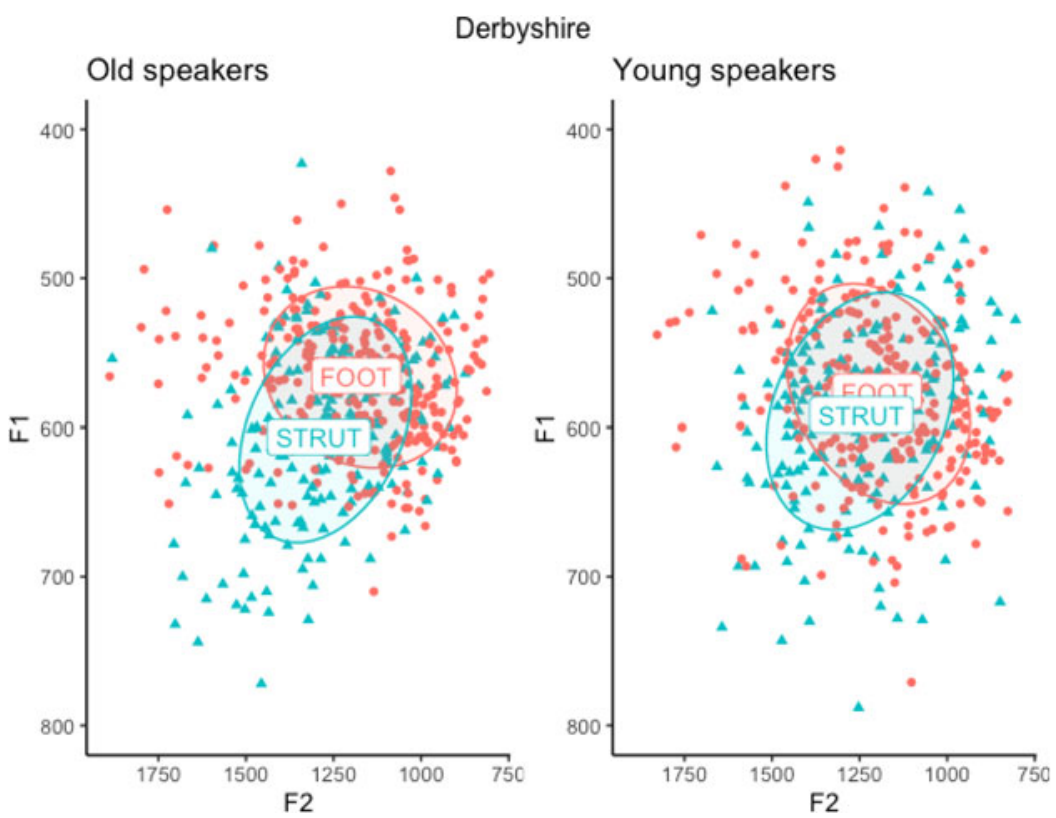

Figure 3. Overlap of FOOT and STRUT in Derbyshire according to age group; Old speakers:

Bhattacharyya's Affinity .9165; Young speakers: Bhattacharyya's Affinity .9597 
Table 5. Bhattacharyya's Affinity (BA) for the individual speaker in the Derbyshire sample (Pseudonym coding: $D=$ Derbyshire, $O=$ old, $Y=$ young, $M=$ male,

$$
F=\text { female) }
$$

\begin{tabular}{lclclllc}
\hline \hline Speaker & BA & Speaker & BA & Speaker & \multicolumn{1}{c}{ BA } & Speaker & BA \\
\hline DOM1 & 0.8925133 & DOF1 & 0.7628573 & DYM1 & 0.9223414 & DYF1 & 0.9313322 \\
DOM2 & 0.9661883 & DOF2 & 0.9022049 & DYM2 & 0.90429 & DYF2 & 0.9099797 \\
DOM3 & 0.8968358 & DOF3 & 0.8755241 & DYM3 & 0.9413219 & DYF3 & 0.8916205 \\
DOM4 & 0.8591291 & DOF4 & 0.8250768 & DYM4 & 0.9519424 & DYF4 & 0.9544982 \\
DOM5 & 0.7658463 & DOF5 & 0.9235225 & DYM5 & 0.8878762 & DYF5 & 0.9265126 \\
\hline \hline
\end{tabular}

sample shows a complete separation of FOOT and STRUT, which again could be explained by Turton \& Baranowski's findings. Welch's two-sample $t$-test of Bhattacharyya's Affinity for the two age groups returns significant at $p=0.0293$, i.e. a change in progress based on the degree of overlap is observable. Figure 4 displays the speakers with the highest Bhattacharyya's Affinity, which is DOM2 and the lowest Bhattacharyya's Affinity, which is DOF1 in the Derbyshire sample. Both speakers belong to the older group of speakers, which indicates that a high level of interspeaker variation exists for this age group.
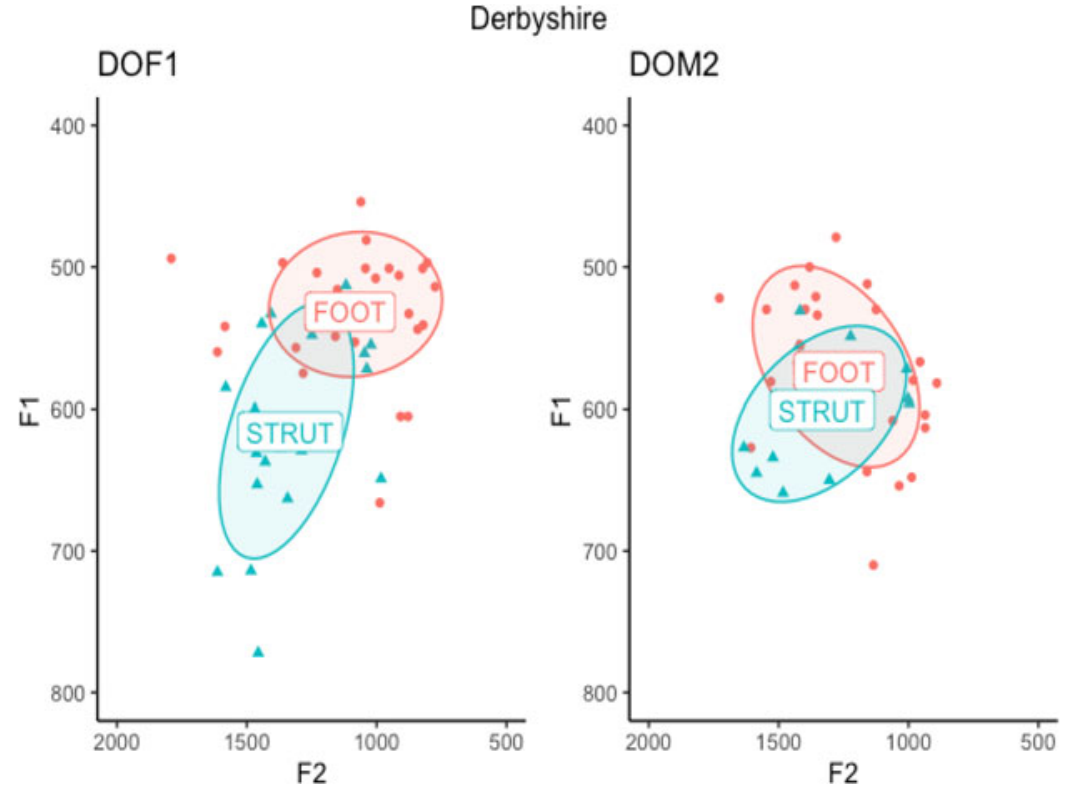

Figure 4. Derbyshire individual with the least overlap (left; Bhattacharyya's Affinity 0.7628573 ) and the most overlap (right; Bhattacharyya's Affinity 0.9661883 ) 


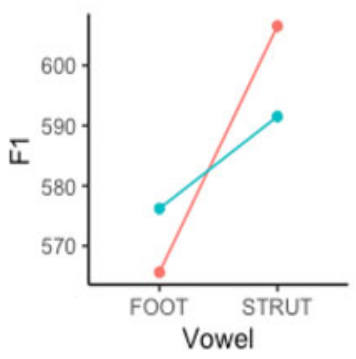

\section{Derbyshire F1 Interactions}

Age group

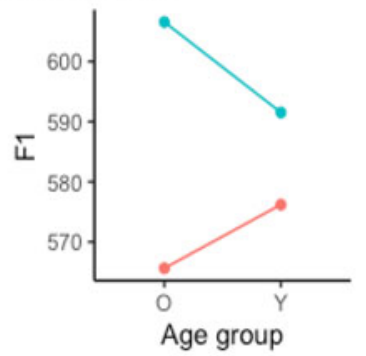

Vowel

$\rightarrow 0 \quad-\quad$

$\rightarrow Y$

Age group

Derbyshire F2 Interactions
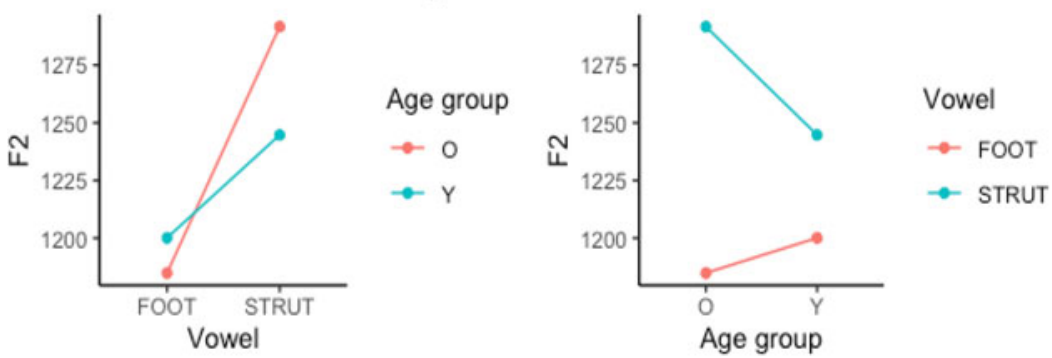

Figure 5. Interaction of vowel and age group for F1 and F2 in Derbyshire

Figure 5 provides the interactions for F1 (top) and F2 (bottom) in Derbyshire. Younger speakers have higher F1 values (i.e. lowering) for ғOOT than older speakers. At the same time, F1 for STRUT decreases, i.e. the vowel is raised in apparent time. Furthermore, the average values for FOOT and STRUT also become more similar. There are also some changes observable for F2. The average F2 value for FOоT increases slightly, which means that FООт is produced marginally further front by younger speakers than by older speakers. The average value does not vary to any great extent between younger and older speakers but we also see STRUT retracting in considerable measures.

In a similar pattern to Derbyshire, the Nottinghamshire dataset (see figure 6) illustrates an increased overlap between FOOT and STRUT; however, the Bhattacharyya's Affinity according to age group is not significant (Welch's $t$-test, $\mathrm{p}=0.3603$ ), i.e. the degree of overlap is not significantly different in apparent time. The Bhattacharyya's Affinity for the individual speakers reveals that there are three speakers who have a Bhattacharyya's Affinity score of lower than 0.7 (see table 6). Comparing these scores with the data from Derbyshire, only one speaker there has a score lower than 0.8 , and all other speakers have a higher score. Hence, interspeaker variation is higher in Nottinghamshire and variation in the overlap of FOOT and STRUT seems to exist between these two counties.

Figure 7 provides detail about interspeaker variation in the Nottinghamshire data. While the older male speaker (NOM2) has a Bhattacharyya's Affinity of 0.5015224, the young male speaker (NYM5) has a very high overlap rate of 0.9636763 . The changes in F1 for both vowels are fairly slim but the plots in figure 8 reveal that F2 is 

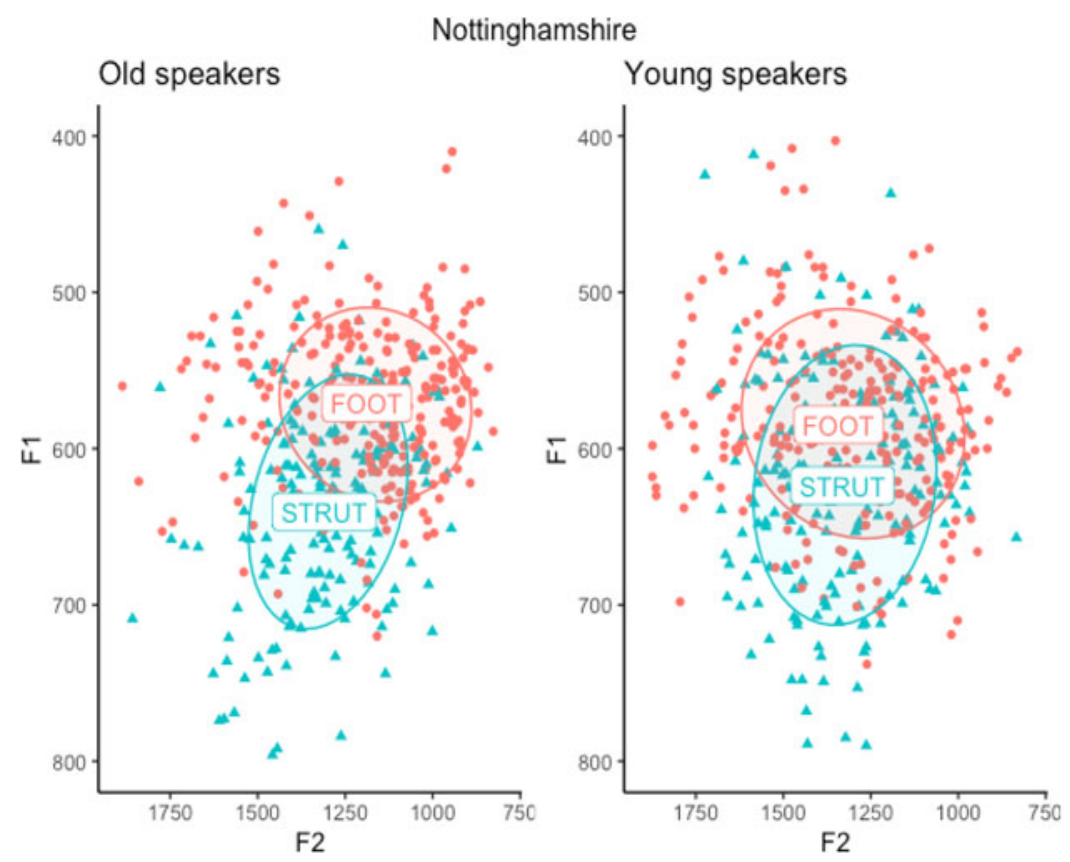

Figure 6. Overlap of FOOT and STRUT in Nottinghamshire according to age group; Old speakers: Bhattacharyya's Affinity .8501675; Young speakers: Bhattacharyya’s Affinity .9238492

Table 6. Bhattacharyya's Affinity (BA) for the individual speaker in the Nottinghamshire sample (Pseudonym coding: $N=$ Nottinghamshire, $O=$ old, $Y=$ young, $M=$ male, $F=$ female)

\begin{tabular}{lllccccc}
\hline \hline Speaker & \multicolumn{1}{c}{ BA } & Speaker & \multicolumn{1}{c}{ BA } & Speaker & BA & Speaker & \multicolumn{1}{c}{ BA } \\
\hline NOM1 & 0.95234 & NOF1 & 0.8272678 & NYM1 & 0.8924713 & NYF1 & 0.8924882 \\
NOM2 & 0.5015224 & NOF2 & 0.8791157 & NYM2 & 0.5436345 & NYF2 & 0.8873889 \\
NOM3 & 0.8266961 & NOF3 & 0.8810578 & NYM3 & 0.8606689 & NYF3 & 0.9441234 \\
NOM4 & 0.813574 & NOF4 & 0.662378 & NYM4 & 0.8331135 & NYF4 & 0.8222013 \\
NOM5 & 0.9148425 & NOF5 & 0.7438428 & NYM5 & 0.9636763 & NYF5 & 0.8924693 \\
\hline \hline
\end{tabular}

changing more in FOOT than in STRUT in apparent time. In fact, FOOT F2 increases quite dramatically for the young speakers, i.e. FOOT is fronting in this setting. The young speakers' FOOT F2 is partly even higher than for sTRUT. The findings suggest that it is not the case that FOOT is the anchor with STRUT changing, but that there seems to be considerable movement in the FOOT vowel as well.

Coming to the Leicestershire data, again we see an increase of overlap between FOOT and STRUT for the younger speakers compared to the older speakers (see figure 

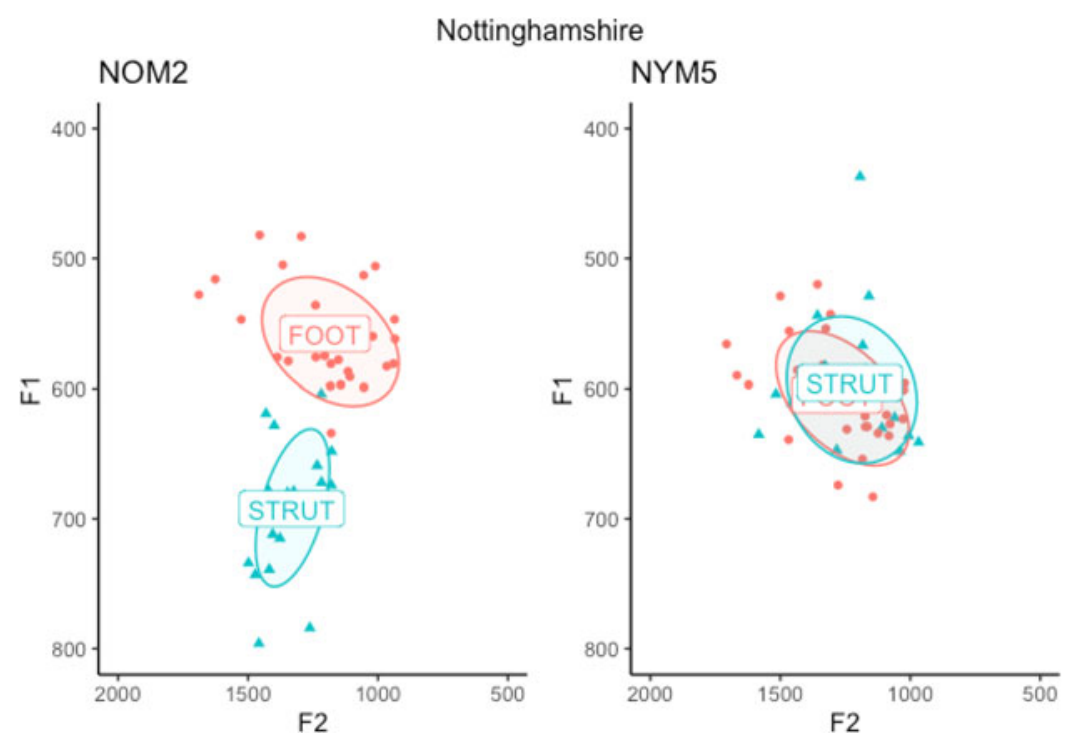

Figure 7. Nottinghamshire individual with the least overlap (left; Bhattacharyya's Affinity 0.5015224) and the most overlap (right; Bhattacharyya's Affinity 0.9636763)

9). Table 7 shows that only one speaker has a Bhattacharyya's Affinity of less than 0.7 and the speaker with the highest overlap score has a score of 0.9881098 (see figure 10), which means that the overlap between FOOT and STRUT is almost
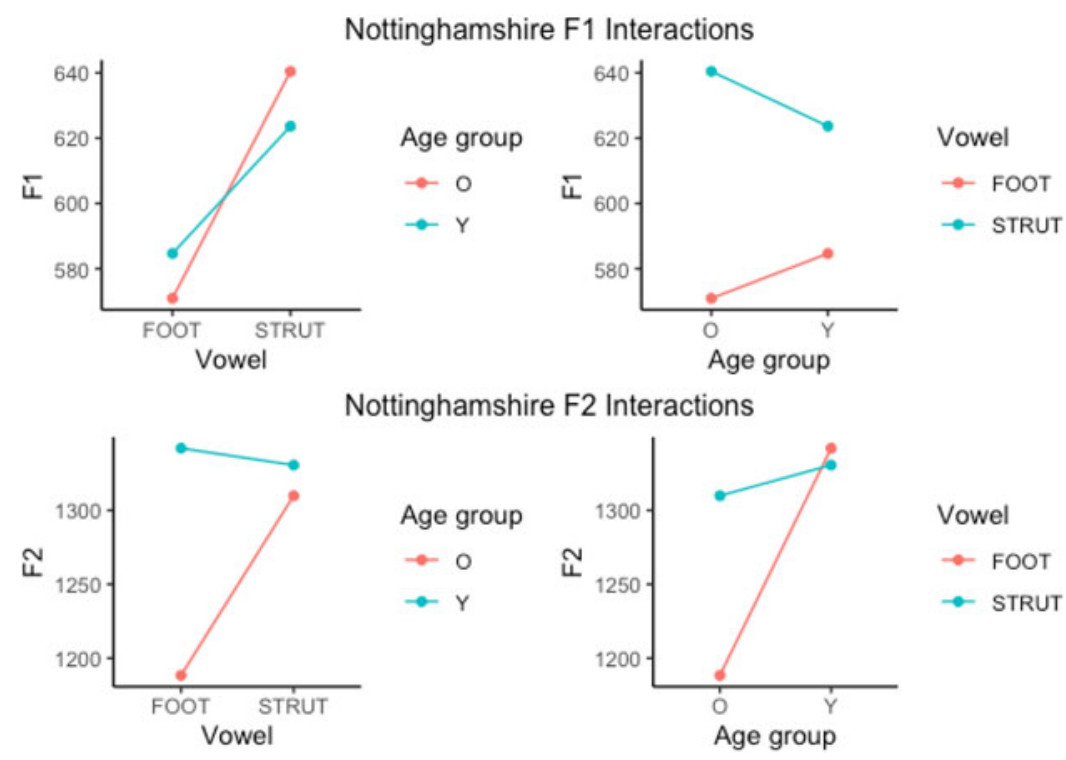

Figure 8. Interaction of vowel and age group for F1 and F2 in Nottinghamshire 

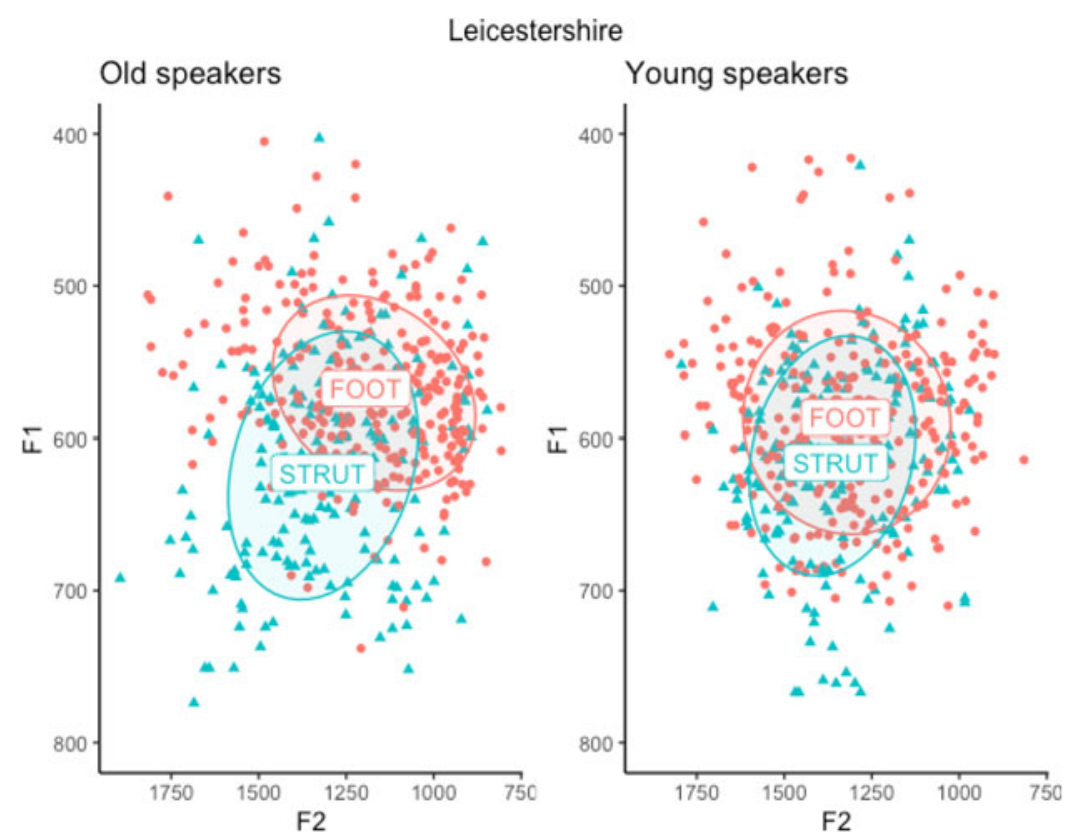

Figure 9. Overlap of FOOT and STRUT in Leicestershire according to age group; Old speakers: Bhattacharyya's Affinity 0.8841179; Young speakers: Bhattacharyya's Affinity 0.9497770

Table 7. Bhattacharyya's Affinity (BA) for the individual speaker in the Leicestershire sample (Pseudonym coding: $L=$ Leicestershire, $O=$ old, $Y=$ young, $M=$ male, $F=$ female)

\begin{tabular}{lclclllc}
\hline \hline Speaker & BA & Speaker & \multicolumn{1}{c}{ BA } & Speaker & \multicolumn{1}{c}{ BA } & Speaker & BA \\
\hline LOM1 & 0.8778542 & LOF1 & 0.6559476 & LYM1 & 0.8695134 & LYF1 & 0.9666903 \\
LOM2 & 0.7669219 & LOF2 & 0.7568527 & LYM2 & 0.918321 & LYF2 & 0.9387908 \\
LOM3 & 0.9562361 & LOF3 & 0.7095721 & LYM3 & 0.8696454 & LYF3 & 0.7358457 \\
LOM4 & 0.8699879 & LOF4 & 0.7602974 & LYM4 & 0.9397128 & LYF4 & 0.8945513 \\
LOM5 & 0.9394221 & LOF5 & 0.916847 & LYM5 & 0.9205675 & LYF5 & 0.9881098 \\
\hline \hline
\end{tabular}

complete. Unlike in the other two counties, the difference in Bhattacharyya's Affinity between age groups is approaching significance at $p=0.0538$. The increase in overlap is especially observable between the older and the younger women in table 7 . Four out of five older women have an overlap measurement of around 0.7, while three younger women have a Bhattacharyya's Affinity higher than 0.9. If there is a tendency for STRUT to split from FOOT, the older (then younger) women in Leicestershire are probably the group who were the leading 

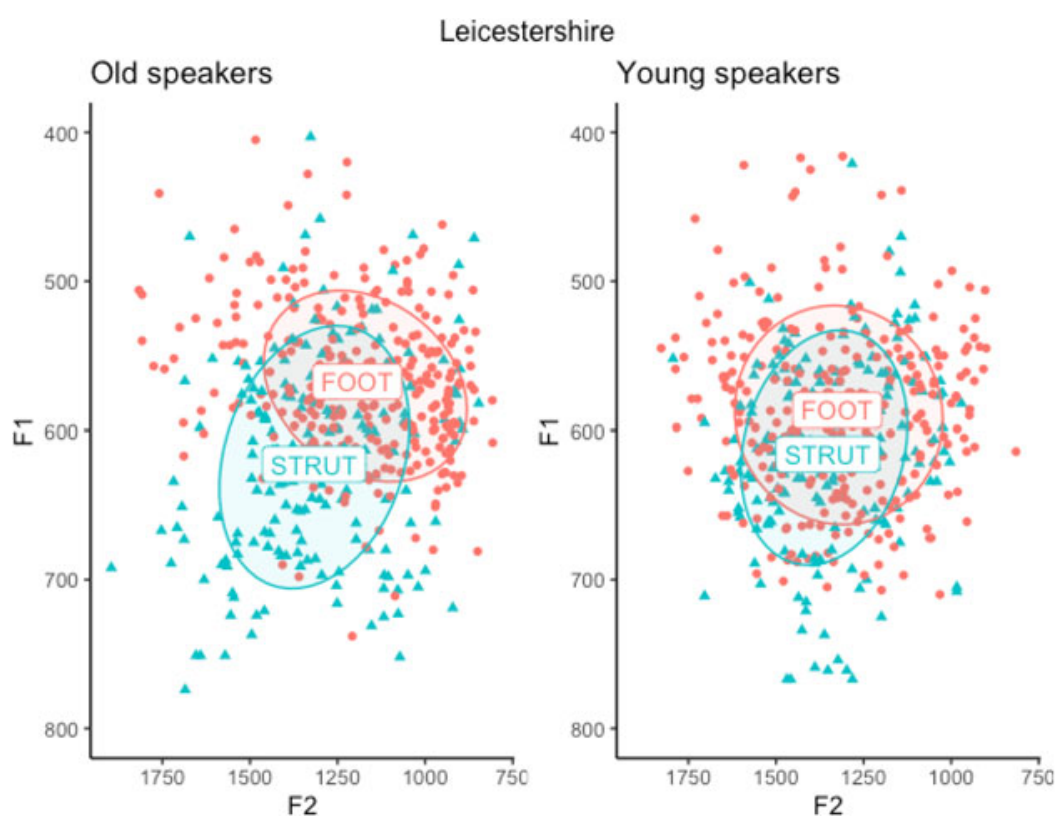

Figure 10. Leicestershire individual with the least overlap (left; Bhattacharyya's Affinity 0.6559476) and the most overlap (right; Bhattacharyya's Affinity 0.9881098)

agents of this change. Zooming in on sex differences in Leicestershire, figure 12 shows that F1 movement in STRUT does not vary much between older and younger women other than a decline in variation in this dataset, suggesting the split seems to have come to a halt while FOOT-fronting then drove the change towards an increase in overlap. While FOOT F2 in Nottingham is partly higher (i.e. fronter in the oral cavity) than STRUT F2 (figure 8), in Leicestershire FOOT F2 is approaching STRUT F2 across apparent time but is still realised further back than STRUT. Figure 12 also reveals that women are driving the change towards FOOT-fronting in Leicestershire.

Overall, the data provide details about interactions for F1 and F2 in the dataset. Figures 5, 8 and 11 illustrate the interaction of vowel and age group for F1 in Derbyshire, Nottinghamshire and Leicestershire respectively. In all three counties, the F1 values of FOOT and STRUT are converging to some extent in apparent time, i.e. F1 for STRUT is decreasing while F1 for FOOT is increasing.

Comparing the interactions for F2 between the three locations reveals a slightly more complex situation. In Leicestershire and Nottinghamshire F2 for STRUT is increasing slightly in apparent time. In Derbyshire on the other hand, we see a countermovement, i.e. the retraction of STRUT. FOOT F2 is increasing (i.e. FOOT is fronting) in all three counties albeit to different degrees. The least fronting occurs in Derbyshire, while a strong increase of F2 is observable for Nottinghamshire where FOOT is partly fronter than STRUT for young speakers. 


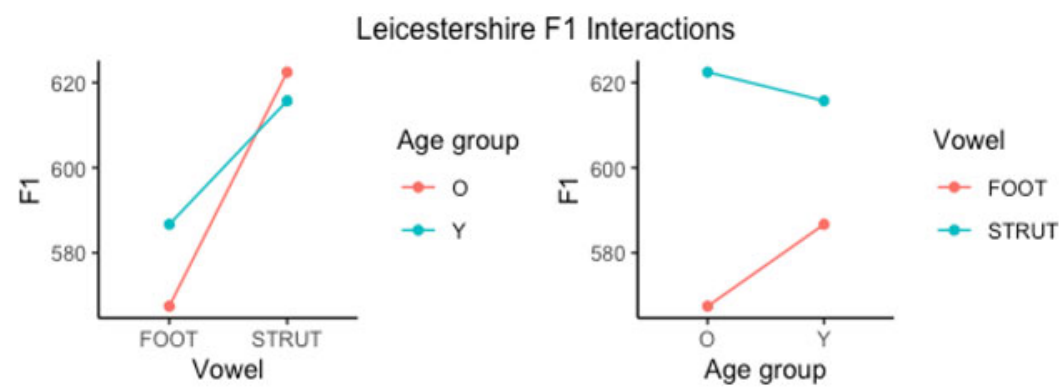

Leicestershire F2 Interactions
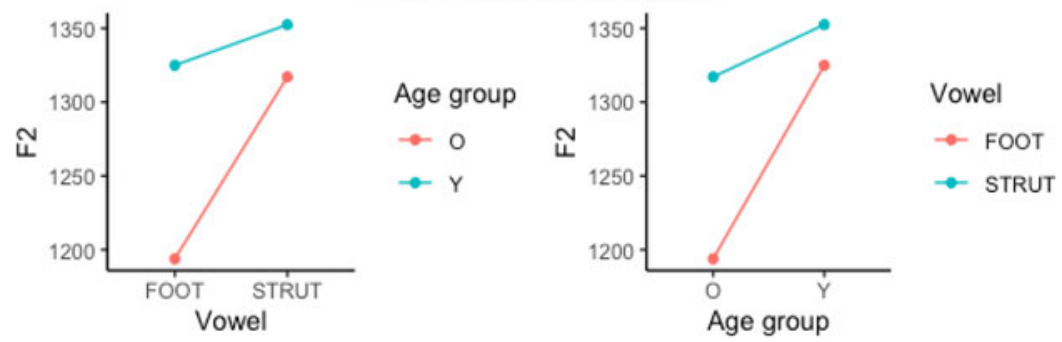

Figure 11. Interaction of vowel and age group for F1 and F2 in Leicestershire

\section{Statistical analysis}

In order to gain a more in-depth understanding of predictor strength as well as potential predictor interaction, a series of linear mixed-effects models was run to fit the best

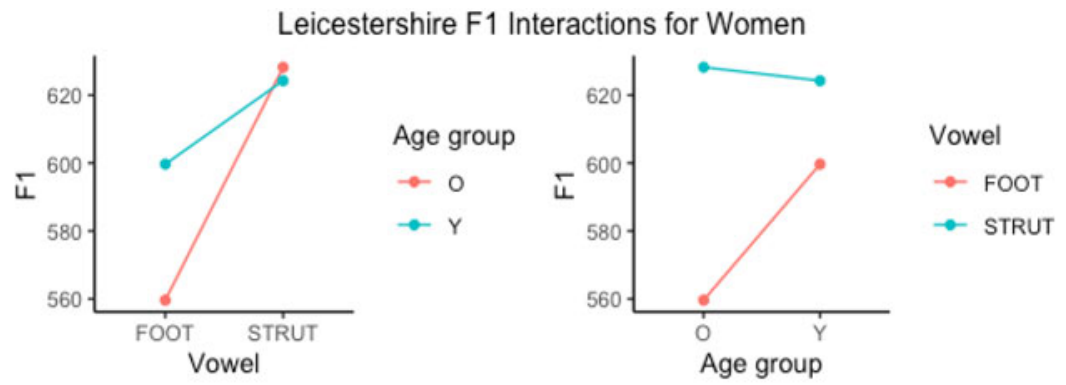

Leicestershire F1 Interactions for Men
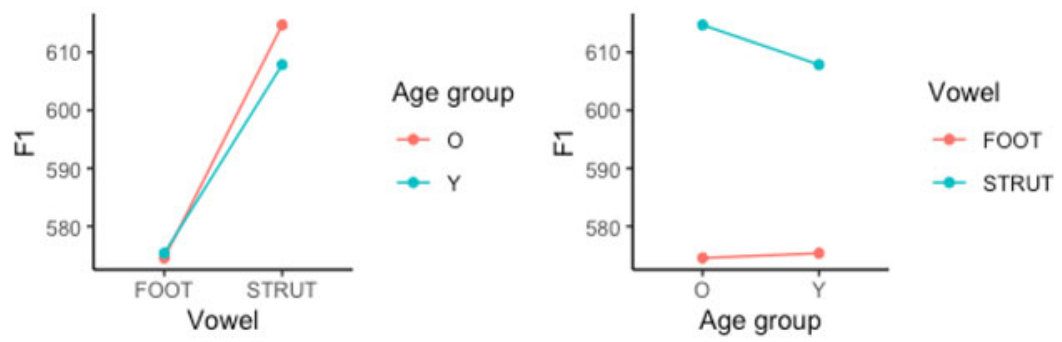

Figure 12. Interaction of vowel and age group for F1 and F2 in Leicestershire according to sex 
Table 8. Independent variables and factors in the statistical model

\begin{tabular}{ll}
\hline \hline Independent variables & Factors \\
\hline vowel & FOOT/sTRUT \\
county & Derbyshire, Leicestershire, Nottinghamshire \\
sex & F, M \\
age group & young, old \\
preceding segment & voiced stop, /w/, other \\
word frequency & subtlex \\
run & 1st reading, 2nd reading \\
following place & alveolar, bilabial, dental, postalveolar, velar \\
following manner & obstruent, sonorant, affricate \\
following voice & voiced, voiceless \\
duration & continuous \\
\hline \hline
\end{tabular}

model. Table 8 provides the factors which were coded for in the study: county, sex, age group and reading were coded as language-external factors, while vowel, preceding segment, word frequency, following place, following manner, following voicing and duration were coded as linguistic factors. These factors are broadly based on findings by Britain (2015) and Turton \& Baranowski (2020). Word frequency is operationalised as a centred Zipf-scaled frequency from the SUBTLEX-UK corpus (van Heuven et al. 2014). First and second readings were coded for in order to detect if significant differences between the two readings occurred which could indicate that the speakers adjust their speech because they realised which sounds we were investigating. In none of the models was this factor significant, which means that the speakers did not change/adjust their pronunciation for FOOT and STRUT. Turton \& Baranowski (2020) only conduct statistical modelling for F1 as they state that only height is relevant for the FOOT-STRUT split. As was shown above, F2 in FOOT sees the most dramatic changes, while F1 and F2 in STRUT are comparatively stable in apparent time. Hence, we fit a series of models for both F1 and F2 in order to investigate this complex set of changes with STRUT as intercept for F1 and FOOT as intercept for F2.

Appendices 2 and 3 provide the mixed-effects models including interactions for $\mathrm{F} 1$ and F2 for the overall sample.

\subsection{Results for $\mathrm{F} 1$}

Breaking down the sample into the different county samples, tables 9-14 provide the final mixed-effects models for Derbyshire, Nottinghamshire and Leicestershire. We investigate F1 variation for STRUT and F2 for FOOT. The results for F1 are discussed first. Linguistic factors which are significant in all three counties are preceding segment and duration. In addition, vowel class is significant, i.e. F1 is significantly different in FOOT and STRUT in each of the three counties. Turton \& Baranowski (2020: 21f.) similarly find this 
Table 9. Mixed-effects linear regression on Derbyshire F1 values of the overall sample by vowel, age group, sex, preceding segment, duration and the interaction between vowel and age group and vowel, age group and sex. Random intercepts for speaker and word are included. $N=949$

\begin{tabular}{|c|c|c|c|c|c|c|}
\hline Fixed effects & Estimate & Std error & $\mathrm{df}$ & $\mathrm{T}$ value & $P$ value & \\
\hline $\begin{array}{l}\text { (Intercept) } \\
\text { Vowel } \\
\text { STRUT (baseline) }\end{array}$ & 634.3692 & 16.7335 & 324.4488 & 37.910 & $<2 \mathrm{e}-16$ & $* * *$ \\
\hline $\begin{array}{l}\text { FOOT } \\
\text { Age group } \\
\text { Old (baseline) }\end{array}$ & -41.0036 & 10.9371 & 46.4700 & -3.749 & 0.000491 & $* * *$ \\
\hline $\begin{array}{l}\text { Young } \\
\text { Sex } \\
\text { F (baseline) }\end{array}$ & -20.9776 & 9.3711 & 45.5506 & -2.239 & 0.030116 & $*$ \\
\hline $\begin{array}{l}\text { M } \\
\text { Preceding segment } \\
\text { Other (baseline) }\end{array}$ & 14.1159 & 9.5983 & 49.3870 & 1.471 & 0.147724 & \\
\hline Voiced stop & -0.6726 & 11.8109 & 27.1296 & -0.057 & 0.955004 & \\
\hline$/ \mathrm{w} /$ & -46.6851 & 14.9984 & 26.5515 & -3.113 & 0.004403 & $* *$ \\
\hline Duration & 27.0223 & 11.6795 & 908.0821 & 2.314 & 0.020909 & $*$ \\
\hline ғоот: male & 0.8782 & 9.5025 & 915.1672 & 915.1672 & 0.926387 & \\
\hline FОот: young & 36.5334 & 9.2262 & 905.1885 & 3.960 & $8.09 \mathrm{e}-05$ & $* * *$ \\
\hline Male: young & 14.2544 & 13.5735 & 49.6556 & 49.6556 & 0.298726 & \\
\hline FООт: young: male & -27.1719 & 13.3970 & 909.8703 & -2.028 & 0.042829 & $*$ \\
\hline Random intercepts & Variance & Std dev. & & & & \\
\hline $\begin{array}{l}\text { Word } \\
\qquad \mathrm{N}=29\end{array}$ & 425.95 & 20.639 & & & & \\
\hline $\begin{array}{l}\text { Speaker } \\
\mathrm{N}=20\end{array}$ & 90.96 & 9.537 & & & & \\
\hline
\end{tabular}

statistical distinction in Manchester, even though the speakers who were included in the sample did not make a distinction between the two vowel categories in a minimal pair test.

Duration is significant in all three counties with longer vowels having higher F1 values. This is also in line with Turton \& Baranowski's (2020: 23) finding for Manchester English. They argue that the jaw has more time to open to produce the vowel, which seems to be the case here as well.

In all three counties preceding /w/ was a significant factor, while voiced stops and $/ \int /$ are not found to be significant preceding environments in this study. Turton \& Baranowski (2020: 22) argue that some form of lip-rounding is part of the production which matches the realisation of STRUT as rounded / $/ \mathrm{v}$ vowel in Manchester English. In the East Midlands data set all tokens which contain preceding $/ \mathrm{w} /$ belong to the FOOT vowel. The limited number of lexical items in 
Table 10. Mixed-effects linear regression on Derbyshire F2 values of the overall sample by vowel, age group, sex, following place, following voicing, duration and the interaction between vowel and age group and vowel and sex. Random intercepts for speaker and word are included. $N=949$

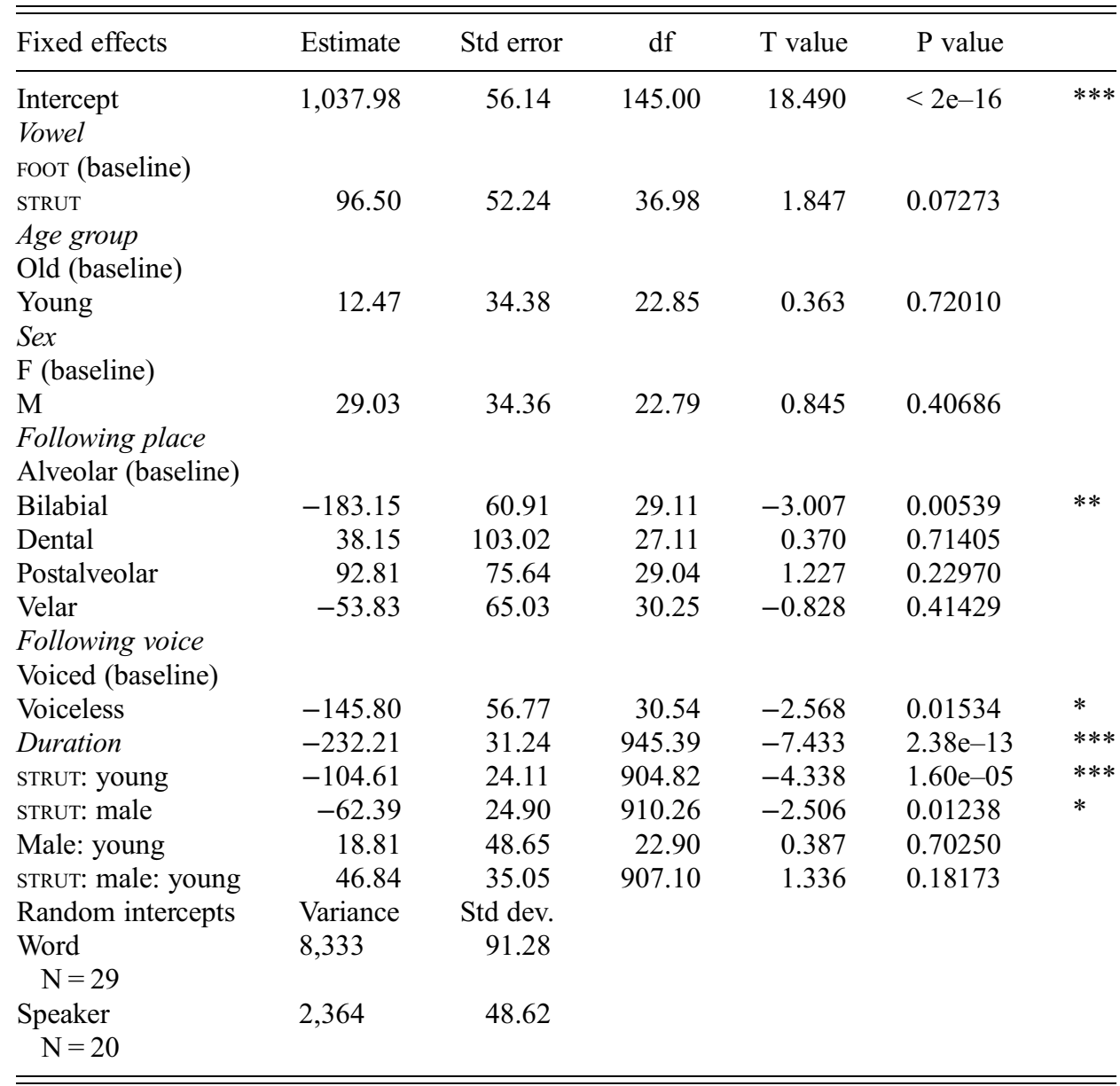

this study due to the collection method might have an influence on the limited explanatory power of this linguistic constraint.

Age group as an external factor is significant for Derbyshire and Nottinghamshire at the level of $\mathrm{p}<0.05$, which is an indicator that we observe a change in progress but it is not significant in Leicestershire, i.e. STRUT F1 in Leicestershire does not differ significantly between the age groups, as also shown in figures 11 and 12. In none of the three counties is sex statistically significant for variation in F1. However, the factor surfaces in interactions with age and vowel in all three counties, suggesting that (young) men 
Table 11. Mixed-effects linear regression on Nottinghamshire F1 values of the overall sample by vowel, age group, sex, preceding segment, duration and the interaction between vowel and age group and vowel, sex and age group. Random intercepts for speaker and word are included.

$$
N=917
$$

\begin{tabular}{|c|c|c|c|c|c|c|}
\hline Fixed effects & Estimate & Std error & df & $\mathrm{T}$ value & $\mathrm{P}$ value & \\
\hline $\begin{array}{l}\text { Intercept } \\
\text { Vowel } \\
\text { STRUT (baseline) }\end{array}$ & 673.135 & 18.443 & 274.017 & 36.499 & $<2 \mathrm{e}-16$ & $* * *$ \\
\hline $\begin{array}{l}\text { FООт } \\
\text { Age group } \\
\text { Old (baseline) }\end{array}$ & -65.950 & 10.465 & 64.506 & -6.302 & $2.98 \mathrm{e}-08$ & $* * *$ \\
\hline $\begin{array}{l}\text { Young } \\
\text { Sex } \\
\text { F (baseline) }\end{array}$ & -25.991 & 12.614 & 34.585 & -2.060 & 0.04694 & $*$ \\
\hline $\begin{array}{l}\text { M } \\
\text { Preceding segment } \\
\text { Other (baseline) }\end{array}$ & -10.255 & 12.540 & 33.785 & -0.818 & 0.41920 & \\
\hline $\begin{array}{l}\text { Voiced stop } \\
/ \mathrm{w} /\end{array}$ & $\begin{array}{r}8.038 \\
-45.294\end{array}$ & $\begin{array}{l}10.208 \\
12.469\end{array}$ & $\begin{array}{l}20.084 \\
26.739\end{array}$ & $\begin{array}{r}0.787 \\
-3.633\end{array}$ & $\begin{array}{l}0.44023 \\
0.00117\end{array}$ & $* *$ \\
\hline $\begin{array}{l}\text { Duration } \\
\text { FOот: male }\end{array}$ & 27.566 & 12.295 & $\begin{array}{l}759.092 \\
880.229\end{array}$ & 2.242 & 0.02524 & $*$ \\
\hline $\begin{array}{l}\text { FOOT: young } \\
\text { Male: young }\end{array}$ & $\begin{array}{l}56.703 \\
21710\end{array}$ & $\begin{array}{l}10.757 \\
17.745\end{array}$ & $\begin{array}{r}879.196 \\
33.886\end{array}$ & $\begin{array}{l}5.271 \\
1.223\end{array}$ & $\begin{array}{l}1.71 \mathrm{e}-07 \\
0.22958\end{array}$ & $* * *$ \\
\hline $\begin{array}{l}\text { Male: young } \\
\text { FOOT: male: young }\end{array}$ & $\begin{array}{r}21.710 \\
-47.146\end{array}$ & $\begin{array}{l}17 . / 45 \\
14.824\end{array}$ & $\begin{array}{r}53.886 \\
880.457\end{array}$ & $\begin{array}{r}1.225 \\
-3.180\end{array}$ & $\begin{array}{l}0.22958 \\
0.00152\end{array}$ & $* *$ \\
\hline Random intercepts & Variance & Std dev. & & & & \\
\hline $\begin{array}{l}\text { Word } \\
\qquad \mathrm{N}=28\end{array}$ & 261.12 & 16.17 & & & & \\
\hline $\begin{array}{l}\text { Speaker } \\
\mathrm{N}=20\end{array}$ & 227.8 & 15.09 & & & & \\
\hline
\end{tabular}

are retaining the distinction between FOOT and STRUT on the height level for longer than women.

\subsection{Results for F2}

The statistical models for F2 confirm the observations in the data analysis section. F2 is significantly higher for younger speakers in Nottinghamshire and Leicestershire than for older speakers, i.e. younger speakers produce their FOOT vowel further front than older speakers. This finding indicates a change in progress in Nottinghamshire and Leicestershire, while age is not significant in Derbyshire. Similarities between the counties are that sex is not a predictor for the variation in F2 and duration is again significant. If FOOT is followed by a bilabial consonant, the vowel is less fronted. 
Table 12. Mixed-effects linear regression on Nottinghamshire F2 values of the overall sample by vowel, age group, sex, following place, following voicing duration and the interaction between vowel and age group and age group and sex. Random intercepts for speaker and word are included. $N=917$

\begin{tabular}{|c|c|c|c|c|c|c|}
\hline Fixed effects & Estimate & Std error & $\mathrm{df}$ & $\mathrm{T}$ value & $\mathrm{P}$ value & \\
\hline $\begin{array}{l}\text { Intercept } \\
\text { Vowel } \\
\text { FOOT (baseline) }\end{array}$ & $1,007.529$ & 59.098 & 133.725 & 17.048 & $<2 \mathrm{e}-16$ & $* * *$ \\
\hline $\begin{array}{l}\text { STRUT } \\
\text { Age group } \\
\text { Old (baseline) }\end{array}$ & 54.285 & 53.570 & 33.329 & 1.013 & 0.31820 & \\
\hline $\begin{array}{l}\text { Young } \\
\text { Sex } \\
\text { F (baseline) }\end{array}$ & 229.720 & 43.869 & 22.793 & 5.236 & $2.67 \mathrm{e}-05$ & $* * *$ \\
\hline $\begin{array}{l}\text { M } \\
\text { Following place } \\
\text { Alveolar (baseline) }\end{array}$ & 27.563 & 43.489 & 22.024 & 0.634 & 0.53274 & \\
\hline $\begin{array}{l}\text { Bilabial } \\
\text { Dental } \\
\text { Postalveolar } \\
\text { Velar }\end{array}$ & $\begin{array}{r}-125.611 \\
7.481 \\
110.066 \\
3.932\end{array}$ & $\begin{array}{l}60.571 \\
99.723 \\
77.106 \\
68.348\end{array}$ & $\begin{array}{l}26.879 \\
24.879 \\
25.755 \\
25.235\end{array}$ & $\begin{array}{r}-2.074 \\
0.075 \\
1.427 \\
0.058\end{array}$ & $\begin{array}{l}0.04781 \\
0.94080 \\
0.16546 \\
0.95458\end{array}$ & $*$ \\
\hline $\begin{array}{l}\text { Voice } \\
\text { Voiced (baseline) }\end{array}$ & & & & & & \\
\hline $\begin{array}{l}\text { Voiceless } \\
\text { Duration }\end{array}$ & $\begin{array}{l}-196.163 \\
-263.501\end{array}$ & $\begin{array}{l}59.166 \\
32.230\end{array}$ & $\begin{array}{r}25.915 \\
906.038\end{array}$ & $\begin{array}{l}-3.315 \\
-8.176\end{array}$ & $\begin{array}{l}0.00271 \\
9.88 \mathrm{e}-16\end{array}$ & $\begin{array}{l}* * \\
* * *\end{array}$ \\
\hline STRUT: young & -156.185 & 27.232 & $\begin{array}{l}875.579 \\
875616\end{array}$ & -5.735 & $\begin{array}{l}1.34 \mathrm{e}-08 \\
016856\end{array}$ & $* * *$ \\
\hline $\begin{array}{l}\text { STRUT: male } \\
\text { Young: male }\end{array}$ & $\begin{array}{r}-36.421 \\
-138.457\end{array}$ & $\begin{array}{l}26.430 \\
61.597\end{array}$ & $\begin{array}{r}875.616 \\
22.154\end{array}$ & $\begin{array}{l}-1.378 \\
-2.248\end{array}$ & $\begin{array}{l}0.16856 \\
0.03487\end{array}$ & $*$ \\
\hline $\begin{array}{l}\text { STRUT: young: male } \\
\text { Random intercepts }\end{array}$ & $\begin{array}{l}37.894 \\
\text { Variance }\end{array}$ & $\begin{array}{r}37.549 \\
\text { Std dev. }\end{array}$ & 875.813 & 1.009 & 0.31316 & \\
\hline $\begin{array}{l}\text { Word } \\
\qquad \mathrm{N}=28\end{array}$ & 7,640 & 87.41 & & & & \\
\hline $\begin{array}{l}\text { Speaker } \\
\mathrm{N}=20\end{array}$ & 4,043 & 63.58 & & & & \\
\hline
\end{tabular}

Similarly, this is the case if the following segment is voiceless (segments covered in the text passage: / $\mathrm{p} \mathrm{k} \mathrm{f/).} \mathrm{Torgersen} \mathrm{(2002)} \mathrm{observes} \mathrm{that} \mathrm{the} \mathrm{following} \mathrm{voiceless} \mathrm{consonants}$ $/ \mathrm{k} /$ and $/ \mathrm{t} /$ favour FOOT-fronting in the south-east of England but comes to no conclusion as to why this would be the case. The interactions reveal that young men retain a more retracted FOOT vowel than women, i.e. young women are driving the change towards FOOT-fronting. Again, Torgersen (2002) finds a similar pattern with girls driving the change towards FOOT-fronting in the south-east.

The presentation of results shows that we are dealing with a complex system of changes in FOOT and STRUT in the East Midlands. The findings are discussed in the following section. 
Table 13. Mixed-effects linear regression on Leicestershire F1 values of the overall sample by vowel, age group, sex, preceding segment, duration and the interaction between vowel and sex, vowel and age group and vowel, sex and age group. Random intercepts for speaker and word are included. $N=965$

\begin{tabular}{|c|c|c|c|c|c|c|}
\hline Fixed effects & Estimate & Std error & df & $\mathrm{T}$ value & $P$ value & \\
\hline $\begin{array}{l}\text { (Intercept) } \\
\text { Vowel } \\
\text { STRUT (baseline) }\end{array}$ & 667.930 & 19.340 & 192.713 & 34.536 & $<2 \mathrm{e}-16$ & $* * *$ \\
\hline $\begin{array}{l}\text { FOOT } \\
\text { Sex } \\
\text { F (baseline) }\end{array}$ & -59.458 & 10.939 & 49.754 & -5.435 & $1.65 \mathrm{e}-06$ & $* * *$ \\
\hline $\begin{array}{l}\mathrm{M} \\
\text { Age group } \\
\text { Old (baseline) }\end{array}$ & -11.399 & 15.091 & 27.386 & -0.755 & 0.456470 & \\
\hline $\begin{array}{l}\text { Young } \\
\text { Preceding segment } \\
\text { Other }\end{array}$ & -7.628 & 15.236 & 28.435 & -0.501 & 0.620460 & \\
\hline Voiced stop & 5.680 & 11.726 & $\begin{array}{l}23.196 \\
24515\end{array}$ & 0.484 & 0.632660 & \\
\hline $\begin{array}{l}\text { /w/ } \\
\text { Duration }\end{array}$ & $\begin{array}{r}-54.288 \\
37.223\end{array}$ & $\begin{array}{l}14.373 \\
12.257\end{array}$ & $\begin{array}{r}24.515 \\
820.489\end{array}$ & $\begin{array}{r}-3.777 \\
3.037\end{array}$ & $\begin{array}{l}0.000899 \\
0.002466\end{array}$ & \\
\hline FоОт: male & 22.832 & 9.554 & 925.811 & 2.390 & 0.017052 & $*$ \\
\hline FоOт: young & 45.569 & 9.842 & 925.261 & 4.630 & $4.18 \mathrm{e}-06$ & $* * *$ \\
\hline Male: young & 1.878 & 21.370 & 27.523 & 0.088 & 0.930624 & \\
\hline FOOT: male: young & -33.878 & 13.611 & 925.200 & -2.489 & 0.012985 & $*$ \\
\hline $\begin{array}{l}\text { Random intercepts } \\
\text { Word } \\
\quad \mathrm{N}=28\end{array}$ & $\begin{array}{l}\text { Variance } \\
384.0\end{array}$ & $\begin{array}{c}\text { Std dev. } \\
19.60\end{array}$ & & & & \\
\hline $\begin{array}{l}\text { Speaker } \\
\mathrm{N}=20\end{array}$ & 430.4 & 20.75 & & & & \\
\hline
\end{tabular}

\section{Discussion}

The overall finding is that no complete overlap between FOOT and STRUT exists in any of the counties under investigation in the East Midlands, ${ }^{3}$ but we also find that FOOT and STRUT do not pattern homogeneously across the East Midlands. The results in tables 9-14 show that F1 and F2 in Leicestershire and Nottinghamshire are different from those acoustic dimensions in Derbyshire. What we mainly observe is a change in FOOT F2 in Leicestershire and Nottinghamshire and STRUT F2 in Derbyshire, but these separate changes both result in an increased overlap between FOOT and STRUT in the younger speaker group in each of the three counties under investigation. Hence while we see

${ }^{3}$ However, the lack of complete overlap does not mean that every speaker has a phonemic split, as discussed in point 4 below. 
Table 14. Mixed-effects linear regression on Leicestershire F2 values of the overall sample by vowel, age group, sex, following place, following voicing, duration and the interaction between vowel and age group, vowel and sex and vowel, sex and age group. Random intercepts for speaker and word are included. $N=965$

\begin{tabular}{|c|c|c|c|c|c|c|}
\hline Fixed effects & Estimate & Std error & df & $\mathrm{T}$ value & $\mathrm{P}$ value & \\
\hline $\begin{array}{l}\text { Intercept } \\
\text { Vowel } \\
\text { FOOT (baseline) }\end{array}$ & $1,183.91$ & 60.55 & 101.58 & 19.552 & $<2 \mathrm{e}-16$ & $* * *$ \\
\hline $\begin{array}{l}\text { STRUT } \\
\text { Age group } \\
\text { Old (baseline) }\end{array}$ & 126.55 & 60.79 & 30.30 & 2.082 & 0.04591 & $*$ \\
\hline $\begin{array}{l}\text { Young } \\
\text { Sex } \\
\text { F (baseline) }\end{array}$ & 140.31 & 41.93 & 21.61 & 3.346 & 0.00297 & $* *$ \\
\hline $\begin{array}{l}\text { M } \\
\text { Following place } \\
\text { Alveolar (baseline) }\end{array}$ & -6.91 & 41.81 & 21.37 & -0.165 & 0.87029 & \\
\hline $\begin{array}{l}\text { Bilabial } \\
\text { Dental } \\
\text { Postalveolar } \\
\text { Velar }\end{array}$ & $\begin{array}{r}-141.30 \\
-10.48 \\
114.50 \\
-16.56\end{array}$ & $\begin{array}{r}67.09 \\
114.89 \\
88.18 \\
77.20\end{array}$ & $\begin{array}{l}28.09 \\
26.27 \\
26.68 \\
27.00\end{array}$ & $\begin{array}{r}-2.106 \\
-0.091 \\
1.299 \\
-0.215\end{array}$ & $\begin{array}{l}0.04424 \\
0.92802 \\
0.20521 \\
0.83175\end{array}$ & $*$ \\
\hline $\begin{array}{l}\text { Voice } \\
\text { Voiced (baseline) }\end{array}$ & & & & & & \\
\hline Voiceless & -186.59 & 68.04 & 26.60 & -2.742 & 0.01077 & $*$ \\
\hline Duration & -148.53 & 30.10 & 954.26 & -4.935 & $9.46 \mathrm{e}-07$ & $* * *$ \\
\hline STRUT: young & -160.38 & 23.44 & 922.58 & -6.842 & $1.42 \mathrm{e}-11$ & $* * *$ \\
\hline STRUT: male & -128.03 & 22.76 & 922.96 & -5.624 & $2.47 \mathrm{e}-08$ & $* * *$ \\
\hline Male: young & -10.92 & 59.18 & 21.44 & -0.184 & 0.85539 & \\
\hline $\begin{array}{l}\text { STRUT: male: young } \\
\text { Random intercepts }\end{array}$ & $\begin{array}{l}104.72 \\
\text { Variance }\end{array}$ & $\begin{array}{r}32.41 \\
\text { Std dev. }\end{array}$ & 922.26 & 3.231 & 0.00128 & $* *$ \\
\hline $\begin{array}{l}\text { Word } \\
\mathrm{N}=28\end{array}$ & 10,389 & 101.93 & & & & \\
\hline $\begin{array}{l}\text { Speaker } \\
\mathrm{N}=20\end{array}$ & 3,865 & 62.17 & & & & \\
\hline
\end{tabular}

some split tendencies on the phonetic level for the older speaker group, in particular in Leicestershire and Nottinghamshire, the younger groups increase the phonetic overlap.

Based on the present study a number of findings regarding the status of the FOOT-STRUT split in the East Midlands need to be discussed:

1. In all three counties, both vowels, on average, remain further back than where we would consider the midpoint of the vowel space to be, i.e. a schwa-like realisation. The vowel realisation can be described as phonetically intermediate between [ə] and [ $\mathrm{v}$. Chambers \& Trudgill (1998) and Trudgill (1986) proposed that speakers settle on a 
phonetic compromise between the $[\mho]$ and $[\Lambda]$ production for STRUT, i.e. the fudged variant. $[\gamma]$ might indeed be the phonetic form of STRUT; however, speakers in the East Midlands are now also producing FОот in this area. Torgersen (2002 based on Cruttenden 1994) reports less lip rounding for FOOT for some RP speakers; however, we did not include F3 measurements to investigate differences in the use of lip rounding. In the future, an additional analysis of lip rounding in both vowels in the East Midlands is needed to show how complete the overlap in oral gestures between the two vowels really is.

2. In all three counties the overlap between FOOT and STRUT increases in apparent time, i.e. a change towards a phonetic split between FOOT and STRUT is not observable across the two age groups under investigation in this study. This finding is contrary to our expectation that we would observe an increased phonetic distance between FOOT and STRUT in the three counties based on the claims by Trudgill (1986) and the findings by Leemann et al. (2018). However, even though Bhattacharyya's Affinity is an improved measure for investigating vowel overlap, these measurements only tell half of the story. The increased overlap between FOOT and STRUT mainly results from FOOT-fronting and slight lowering. The changes in FOOT and the fairly stable STRUT vowel in Leicestershire and Nottinghamshire are quite surprising as this scenario of change has not been discussed before.

The results in this article suggest that FOOT and STRUT are fronting at different rates in Leicestershire and Nottinghamshire (figures 8, 11 and 12). Since FOOT started in a backer position in vowel space than STRUT, yet ended in a comparably similar position with respect to frontness, it could be argued that FOOT-fronting is advancing faster than STRUT-fronting. Furthermore, STRUT seems to be almost stable across apparent time in those two counties. This is particularly the case for the Nottinghamshire speakers in our dataset. Indeed, for these speakers, very little overall movement of STRUT was observable. Again, this is a surprising finding as we had expected for sTRUT to move in the vowel space, not FOOT.

3. The realisation of FOOT and STRUT in the East Midlands is somewhat variable, with the majority of speakers showing very high rates of overlap, but a few speakers have less overlap in their vowel realisation. However, it comes as a surprise that even with the observed interspeaker variation, the change towards two phonetically completely separated vowels is very limited. Given that the SED already described quite some variation for Leicestershire in the middle of the twentieth century, it seems as if this variation towards a (phonetic) split has not expanded in this county. The somewhat lower overlap measurements for older women in Leicestershire might be a reminiscence of a movement towards the phonetic split.

Another observation is that the overlap between FOOT and STRUT is higher in Leicestershire than in Nottinghamshire though the overlap measurement differences are not statistically significant. This is surprising because Nottinghamshire is located further north than Leicestershire and the SED, MMB and BBC Voices results (shown in table 1) suggest that there is less variation in Nottinghamshire than in Leicestershire. We do not want to make any broad claims about this finding at the moment but leave it for further investigation. Only a more community-based study will provide information about this result. 
4. Speakers of both age groups in Derbyshire show more overlap between FOOT and STRUT than in Leicestershire and Nottinghamshire and they have no significant FOOT-fronting, i.e. speakers in Derbyshire make more conservative choices than the speakers in Leicestershire and Nottinghamshire. The data also show that the overlap between FOOT and STRUT for the individuals in the older speaker group was highest in Derbyshire compared to the older speakers in the other two counties. This information in addition to the findings in the SED led to the assumption that previously FOOT and STRUT were more advanced in undergoing change towards a split in Nottinghamshire and Leicestershire but less so in Derbyshire.

While STRUT is fairly stable or rather fronting slightly in the Leicestershire and Nottinghamshire sample, the vowel is retracting in Derbyshire. Hence, the increase of overlap on the F2 dimension is due to the fronting of FOOT in Leicestershire and Nottinghamshire but due to the retraction of stRuT in Derbyshire. Therefore, diverging trends in the realisation of FOOT and STRUT are observable within the East Midlands. Speakers in Leicestershire and Nottinghamshire seem to participate in a change which has been described for the south-east of England, namely FOOT-fronting, e.g. by Torgersen (2002), Torgersen \& Kerswill (2004) and Fabricius (2007), while Derbyshire speakers seem to pattern more with northern English speakers and even more so in the group of younger speakers.

This finding raises the question of homogeneity in the realisation of FOOT and STRUT but also the phonemic status of the two vowels in the East Midlands. Jansen (2019) makes the observation that FOOT-fronting is only apparent in varieties which have the FOOT-STRUT split. Therefore, FOOT-fronting in Leicestershire and Nottinghamshire could be an indicator that FOOT and STRUT might have developed a separate phonemic status before the innovative increase in phonetic overlap between the vowels. However, this is not the case in Derbyshire as yet. Therefore, we might indeed see a slow northward movement of the FOOT-STRUT split, as predicted by Trudgill (1986), but it manifests phonetically as the fronting of FOOT rather than the realisation of FOOT and STRUT as completely separate phonetic entities.

Admittedly, this study is a broad brush across the East Midlands when it comes to FOOTSTRUT variation. However, the multilocality approach taken here provides initial insights into 'a sound change as it moves through the linguistic system' (Horvath \& Horvath 2001: 37) of the East Midlands. Dimensions such as urban-rural, social class and ethnicity have not been taken into account here but pose important factors - as Drummond (2012) and Turton \& Baranowski (2020) have shown - in understanding variation and change of FOOT-STRUT changes in the East Midlands based on community studies, which we plan to conduct in the future. In addition, this study is based on read data, which might have an influence on the use of vowel variation. Future research needs to incorporate stylistic variation in order to avoid self-conscious changes in the use of STRUT, as reported by Docherty \& Foulkes (1999) for Derby, and to achieve a holistic view on the variation of FOOT and STRUT. The present study should therefore be treated as providing initial insights into the status of FOOT-STRUT variation in this region. 


\section{Conclusion}

This article set out to examine the FOOT-STRUT split in the East Midlands region. We know from the small amount of previous research that the East Midlands is a linguistically interesting region as it falls between the geographical and linguistic north and south. Using earlier dialectological sources allowed us to establish the relationship between FOOT and STRUT in three counties of the East Midlands in the first half of the twentieth century. The results showed us that although for most speakers there was little variation between STRUT and FOOT, there were some indications in Leicestershire (the most southerly county) that the southern $[\Lambda]$ form was infrequently found in STRUT words, as well as a few intermediate variants.

We have argued that at the end of the second decade of the twenty-first century the emerging FOOT-fronting in Leicestershire and Nottinghamshire seems to indicate a northward movement of the phonemic split, while phonetically FOOT and STRUT become more similar. In Derbyshire, on the other hand, not FOOT fronting but STRUT retraction is observed, which leads to the assumption that speakers in this county still retain the lack of the split and cluster with northern English speakers.

Authors' addresses:

Department of English and American Studies

Paderborn University

Warburger Str. 100

33098 Paderborn

Germany

sandra.jansen@uni-paderborn.de

School of Arts and Humanities

Nottingham Trent University

Clifton Campus

Nottingham

NG11 8NS

$U K$

natalie.braber@ntu.ac.uk

\section{References}

Beal, Joan C. 2008. English dialects in the North of England: phonology. In Kortmann \& Upton (eds.), 122-44.

Beal, Joan C. 2010. An introduction to regional Englishes. Edinburgh: Edinburgh University Press.

Beal, Joan C. 2012a. Evidence from sources after 1500. In Terttu Nevailainen \& Elizabeth Closs Traugott (eds.), The Oxford handbook of the history of English, 63-77. New York: Oxford University Press. 
Beal, Joan C. 2012b. 'By those provincials mispronounced': The stRut vowel in eighteenth-century pronouncing dictionaries. Language and History 55(1), 5-17.

Bhattacharyya, Anil Kular. 1943. On a measure of divergence between two statistical populations defined by their probability distributions. Bulletin of the Calcutta Mathematical Society 35, 99-109.

Braber, Natalie. 2014. The concept of identity in the East Midlands of England. English Today 30 (2), 3-10.

Braber, Natalie. 2015. Language perception in the East Midlands. English Today 31(1), 16-26.

Braber, Natalie \& Nicholas Flynn. 2015. The East Midlands: Nottingham. In Raymond Hickey (ed.), Researching Northern English, 369-92. Amsterdam: John Benjamins.

Braber, Natalie \& Jonnie Robinson. 2018. East Midlands English. Berlin: De Gruyter Mouton.

Britain, David. 1991. Dialect and space: A geolinguistic study of speech variables in the Fens. PhD dissertation, University of Essex.

Britain, David. 2002. Space and spatial diffusion. In Jack Chambers, Peter Trudgill \& Natalie Schilling-Estes (eds.), The handbook of language variation and change, 603-37. Oxford: Blackwell.

Britain, David (ed.). 2007. Language in the British Isles. Cambridge: Cambridge University Press.

Britain, David. 2015. Between North and South: The Fenland. In Raymond Hickey (ed.), Researching Northern English, 417-36. Amsterdam: John Benjamins.

Calenge, Clement. 2006. The package adehabitat for the R software: A tool for the analysis of space and habitat use by animals. Ecological Modelling 197, 516-19.

Chambers, J. K. \& Peter Trudgill. 1998. Dialectology, 2nd edn. Cambridge: Cambridge University Press.

Clark, Urszula. 2008. The English West Midlands: Phonology. In Kortmann \& Upton (eds.), 145-77.

Cruttenden, Alan. 1994. Gimson's Pronunciation of English. London: Arnold.

Docherty, Gerard J. \& Paul Foulkes. 1999. Derby and Newcastle: Instrumental phonetics and variationist studies. In Foulkes \& Docherty (eds.), 47-71.

Drummond, Rob. 2012. The Manchester Polish STRUT: Dialect acquisition in a second language. Journal of English Linguistics 41(1), 65-93.

Evanini, Keelan. 2009. The permeability of dialect boundaries: A case study of the region surrounding Erie, Pennsylvania. PhD dissertation, University of Pennsylvania.

Fabricius, Anne. 2007. Vowel formants and angle measurements in diachronic sociophonetic studies: foot-fronting in RP. Proceedings of the 16th International Congress of Phonetic Sciences, 1477-80.

Ferragne, Emmanuel \& François Pellegrino. 2010. Formant frequencies of vowels in 13 accents of the British Isles. Journal of the International Phonetic Association 40(1), 1-34.

Flynn, Nicholas. 2012. A sociophonetic study of Nottingham speakers. PhD dissertation, University of York.

Foulkes, Paul \& Gerard Docherty (eds.). 1999. Urban voices. London: Arnold.

Harris, John. 1996. On the trail of short $u$. English World-Wide 17(1), 1-42.

Hay, Jennifer, Paul Warren \& Katie Drager. 2006. Factors influencing speech perception in the context of a merger-in-progress. Journal of Phonetics 34, 458-84.

Herold, Ruth. 1990. Mechanisms of merger: The implementation and distribution of the low back merger in eastern Pennsylvania. PhD dissertation, University of Pennsylvania.

Horvath, Barbara M. \& Ronald J. Horvath. 2001. A multilocality study of a sound change in progress: The case of /1/ vocalization in New Zealand and Australian English. Language Variation and Change 13(1), 37-57.

Hughes, Arthur, Peter Trudgill \& Dominic Watt. 2005. English accents and dialects, 4th edn. London: Hodder Arnold. 
Jansen, Sandra. 2019. Change and stability in GOOSE, GOAT and FOOT: Back vowel dynamics in Carlisle English. English Language and Linguistics 23(1), 1-29.

Johnson, Daniel Ezra. 2010. Stability and change along a dialect boundary: The low vowels of southeastern New England. Publication of the American Dialect Society 95. Durham, NC: Duke University Press.

Johnson, Daniel Ezra. 2015. Quantifying overlap with Bhattacharyya's Affinity and other measures. Presented at NWAV44. https://danielezrajohnson.shinyapps.io/nwav_44/

Kortmann, Bernd \& Clive Upton (eds). 2008. Handbook of varieties of English: The British Isles. Berlin: Mouton de Gruyter.

Leemann, Adrian, Marie-José Kolly \& David Britain. 2018. The English Dialects App: The creation of a crowdsourced dialect corpus. Ampersand 5, 1-17.

Lobanov, Boris M. 1971. Classification of Russian vowels spoken by different speakers. Journal of the Acoustical Society of America 49, 606-8.

MacKenzie, Laurel, George Bailey \& Danielle Turton. 2014. Crowdsourcing dialectology in the undergraduate classroom. Presented at Methods in Dialectology XV, University of Groningen, The Netherlands.

Nycz, Jennifer. 2018. Stylistic variation among mobile speakers: Using old and new regional variables to construct complex place identity. Language Variation and Change 30(2), 175-202.

Nycz, Jennifer \& Lauren Hall-Lew. 2014. Best practices in measuring vowel merger. Proceedings of Meetings on Acoustics 20. http://dx.doi.org/10.1121/1.4894063

Orton, Harold, Eugen Dieth, Willfrid Halliday, Michael Barry, P. M. Tilling \& Martyn Wakelin. 1962-71. Survey of English Dialects: Basic materials. Introduction and 4 vols. (each in 3 parts). Leeds: E. J. Arnold \& Son.

R Core Team. 2015. R: A language and environment for statistical computing [computer program]. Vienna: R Foundation for Statistical Computing. www.R-project.org

Rosenfelder, Ingrid, Josef Fruehwald, Keelan Evanini \& Yuan Jiahong. 2011. FAVE (Forced Alignment and Vowel Extraction) Program Suite.

Sloetjes, Han \& Peter Wittenburg. 2008. Annotation by category: ELAN and ISO DCR. Proceedings of the 6th International Conference on Language Resources and Evaluation. www.lrec-conf.org/proceedings//rec2008/pdf/208_paper.pdf

Stanley, Joseph A. \& Margaret E. L. Renwick. 2016. Phonetic shift /or/ phonemic change? American English mergers over 40 years. Presented at LabPhon 15, Ithaca, NY.

Strelluf, Christopher. 2016. Overlap among back vowels before /1/ in Kansas City. Language Variation and Change 28(3), 379-407.

Strelluf, Christopher. 2018. Speaking from the heartland: The Midland vowel system of Kansas City. Durham, NC: Duke University Press.

Torgersen, Eivind. 2002. Phonological distribution of the foot vowel in young people's speech in south-eastern British English. Reading Working Papers in Linguistics 6, 25-38.

Torgersen, Eivind \& Paul Kerswill. 2004. Internal and external motivation in phonetic change: Dialect levelling outcomes for an English vowel shift. Journal of Sociolinguistics 8(1), 23-53.

Trudgill, Peter. 1983. On dialect: Social and geographical perspectives. London: New York University Press.

Trudgill, Peter. 1986. Dialects in contact. Oxford: Blackwell.

Turton, Danielle \& Maciej Baranowski. 2020. Not quite the same: The social stratification and phonetic conditioning of the FOOT-STRUT vowels in Manchester. Journal of Linguistics, 1-39.

Upton, Clive. 1995. Mixing and fudging in Midland and southern dialects of England: The CUP and FOOT vowels. In Jack Windsor Lewis (ed.), Studies in general and English phonetics, 385-94. London: Routledge. 
Upton, Clive. 2012. The importance of being Janus: Midland speakers and the 'north-south divide'. In Manfred Markus, Yoko Iyeiri, Reinhard Heuberger \& Emil Chamson (eds.), Middle and Modern English corpus linguistics, 257-68. Amsterdam: John Benjamins.

Upton, Clive \& J. D. A. Widdowson. 1996. An atlas of English Dialects. London: BCA. van Heuven, Walter J. B., Pawel Mandera, Emmanuel Keuleers \& Marc Brysbaert. 2014. SUBTLEX-UK: A new and improved word frequency database for British English. Quarterly Journal of Experimental Psychology 67, 1176-90.

Wales, Katie. 2006. Northern English: A social and cultural history. Cambridge: Cambridge University Press.

Warren, Paul. 2018. Quality and quantity in New Zealand English vowel contrasts. Journal of the International Phonetic Association 48(3), 305-30.

Wells, J. C. 1982a. Accents of English, vol. 1: An introduction. Cambridge: Cambridge University Press.

Wells, J. C. 1982b. Accents of English, vol. 2: The British Isles. Cambridge: Cambridge University Press.

Appendix 1: Reading passage

Underlined words $=$ STRUT words; bold words $=$ FOOT words .

Tina and Duncan were really happy. Last Sunday they had visited Newcastle with their father for the day. It was an open day at the university and they were going to have a look at what it would be like to be students at the school of humanities in the far north of the country. After an early start and enjoying the facade of the building they visited student accommodation and the adjacent woods. The cooking facilities were good but the butcher around the corner looked even better. The students asked them to stay for a dance party. Both were very excited but tried to stay calm.

After the visit the staff asked the two southerners if they could imagine moving as far as Newcastle and they happily said yes. This morning they were talking about a funny story in the newspaper. A pub called the Grumpy Duke of Gloucester was in the news for winning the prize for best tuna sandwiches and the pub landlord didn't even like fish. Both were laughing about this story.

As Tina stood in the kitchen in her pyjamas, humming a tune and making a cup of tea, Duncan sat on a cushion enjoying the calm reading through a part of the newspaper and tearing out the special offer to get half price beef stew and mushy peas at his favourite canteen. He pushed the wooden stool away from the table to grab the book from the basket.

A drama, he was supposed to read for the book club tonight though he would have preferred to go to a football match. The book was about famous chefs who can't really cook. 
Appendix 2: Mixed-effects model output of F1 in all three counties including interactions

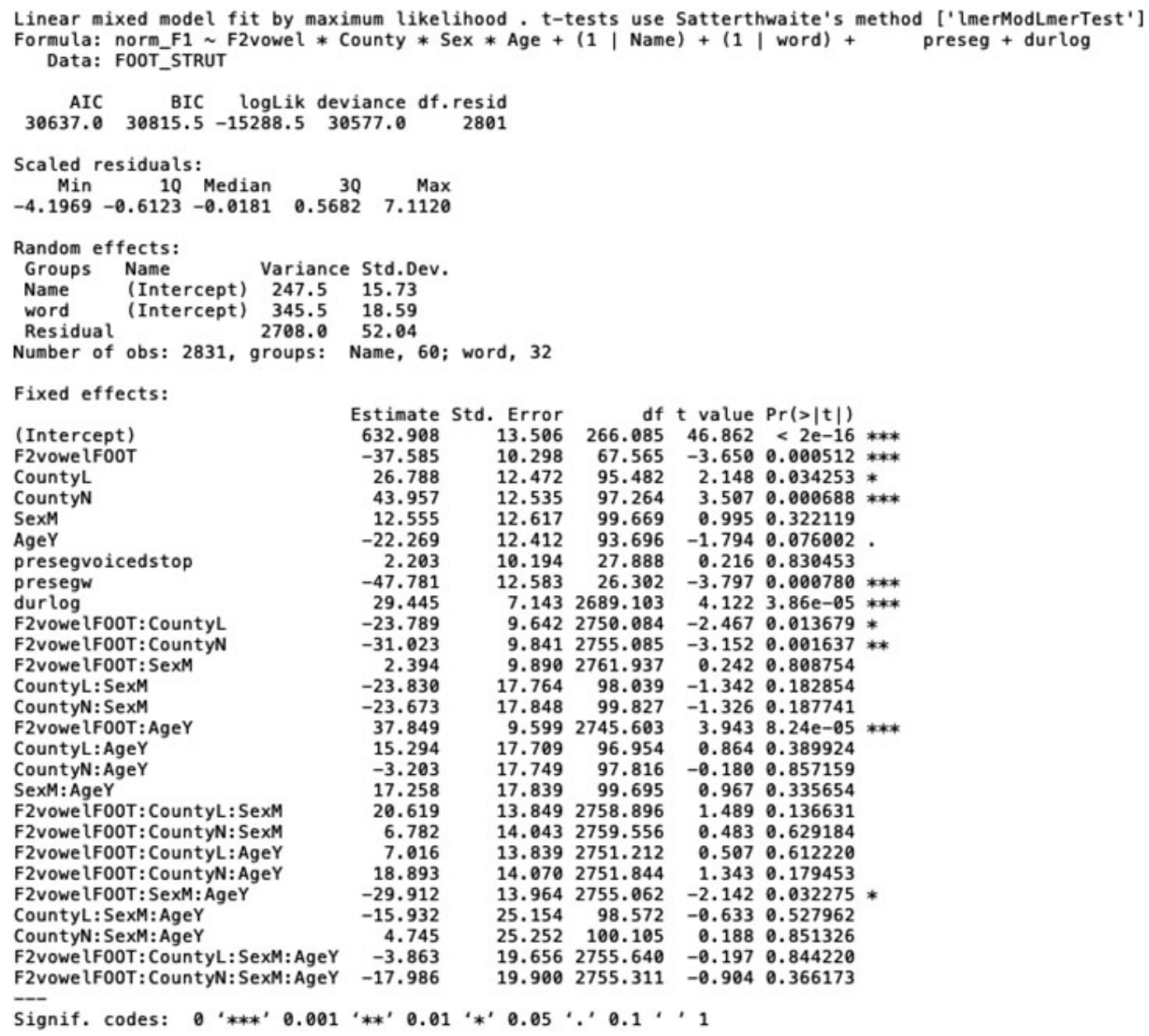


Appendix 3: Mixed-effects model output of F2 in all three counties including interactions

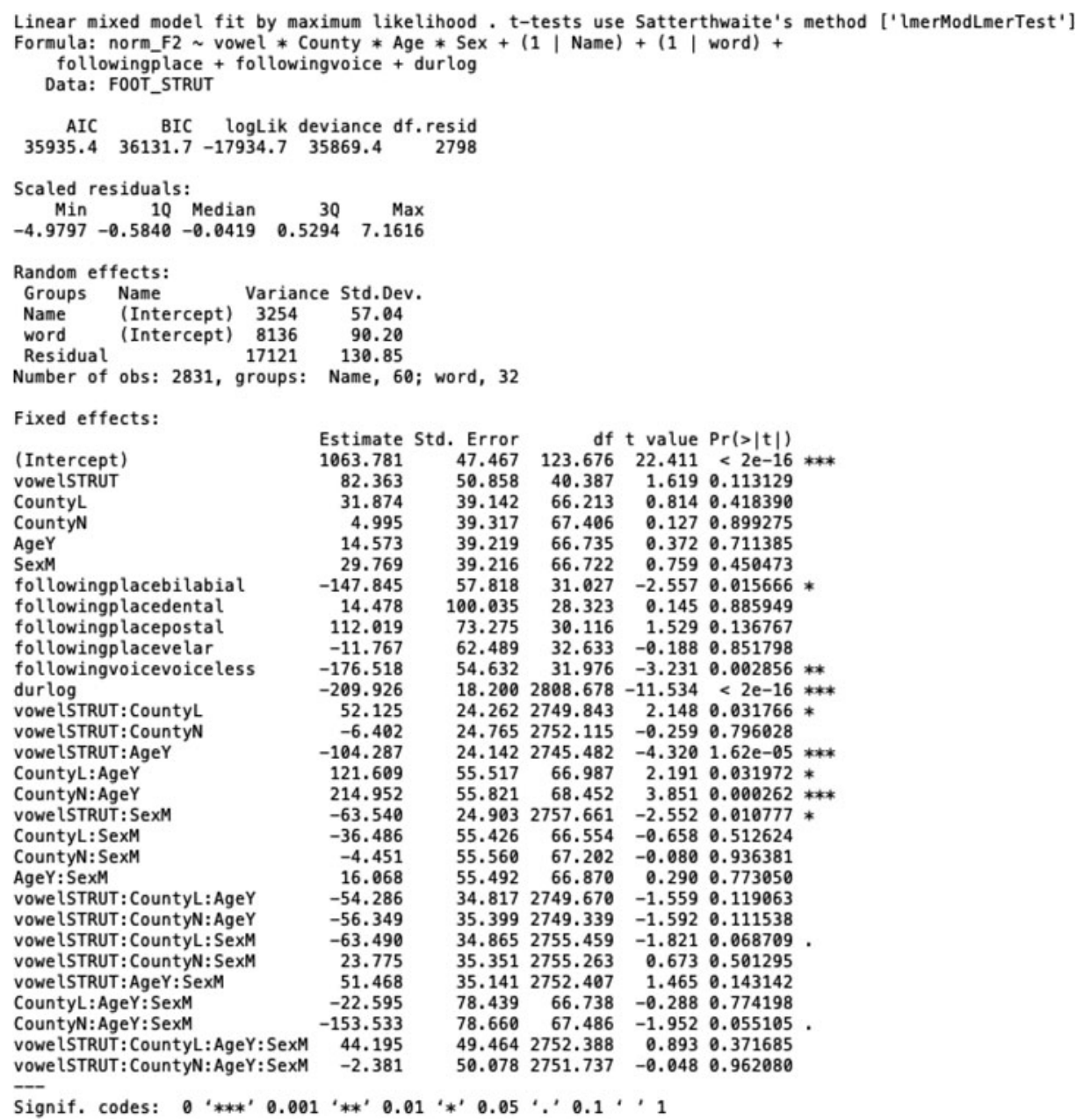

